\title{
Análise espacial da burocracia da assistência social nos municípios brasileiros: notas para uma reflexão sobre a capacidade de implementação dessa política
}

\author{
Natália Guimarães Duarte Sátyro \\ Eleonora Schettini Martins Cunha \\ Járvis Campos
}

\section{Introdução}

Aos 11 anos da criação do Sistema Único de Assistência Social (Suas) ${ }^{1}$, coordenado pelo Ministério do Desenvolvimento Social e Combate à Fome (MDS), uma das perguntas recorrentes entre os interessados na política de assistência social é: como está o processo de implementação dessa política no nível municipal? Trata-se de uma questão relevante, uma vez que a organização descentralizada do Suas reserva aos municípios a oferta de serviços e benefícios de proteção social básica, que devem alcançar a todos aqueles que precisam desse tipo de proteção, em todo o território nacional (Brasil, 2012). Por outro lado, a grande diversidade dos municípios quanto ao desenvolvimento econômico, às características demográficas, à demanda por serviços (derivada das inúmeras expressões de vulnerabilidades e riscos sociais) e às diferentes capacidades estatais indica possíveis obstáculos para que essa oferta seja realizada.

Mas o que conhecemos sobre a capacidade de implementação dos municípios no que se refere à política de assistência social? Essa questão é relevante, dado que cabe ao Estado brasileiro, nos seus três níveis de governo, a primazia da oferta dessa política e, especialmente aos municípios, a entrega de um maior número de serviços de proteção social (Brasil, 2012). Para que essa oferta ocorra, o município deve ter várias capacidades desenvolvidas. Conhecê-las é um desafio empírico que encontra ressonância num amplo debate sobre "capacidades do Estado".

O conceito de capacidades estatais ainda é pouco sistematizado, apesar de ser utilizado por diferentes disciplinas, seja para indicar o que as determina, seja para apontar suas consequências. De modo geral, associa-se a capacidade estatal à habilidade de implantar decisões e conseguir alcançar fins almejados pelo Estado (Gomide, 2016). Numa sugestiva revisão da literatura, Cingolani (2013, p. 27) identifica sete dimensões do poder do Estado nos estudos que trabalham com esse conceito: coercitiva, militar;

\footnotetext{
${ }^{1}$ O Suas foi criado em 15 de julho de 2005 pela Resolução n 130 do Conselho Nacional de Assistência Social (CNAS).
} 
fiscal; administrativa e de implementação; transformativa, de industrialização; relacional, de cobertura territorial; legal; e, por fim, política; todas utilizadas separadamente ou combinadas em estudos de diferentes campos. A multidimensionalidade do conceito tem gerado análises de amplitude variada, desde unidimensionais até as derivadas de índices produzidos a partir de algumas delas (Cingolani, 2013). Além disso, capacidades estatais não são fixas e atemporais, variando no tempo, no espaço e conforme a área de atuação do Estado (Gomide, 2016).

A análise das "capacidades do Estado" associada às políticas públicas pode focar na sua capacidade de formulação e aprovação da política, destacando-se os fatores informacionais, o desenho das políticas e suas regras, a maioria legislativa, a conciliação da política pública com os interesses privados, as políticas prévias, bem como as políticas semelhantes. Também pode ser verificada a capacidade de implementação, destacandose como relevante os fatores financeiros, infraestruturais (recursos materiais e humanos) e de alcance territorial (Souza, 2010). A capacidade do Estado, portanto, está relacionada a fatores políticos, institucionais, administrativos e técnicos (Cingolani, Thomsson e Crombrugghe, 2013). Em todas essas abordagens destaca-se o papel da burocracia, ou seja, as capacidades do Estado dependem da existência de capacidades burocráticas.

No entanto, o estudo sobre a implementação de políticas públicas aponta que uma dimensão essencial para tais análises é a capacidade burocrática do Estado e, nessa perspectiva, torna-se relevante a existência de uma burocracia profissionalizada e estável (Cingolani, 2013), considerada fundamental para que a política se efetive, ou seja, a capacidade burocrática importa. Desde Weber (1978), que estabeleceu as bases para pensar as características e a relevância da estrutura burocrática para que o Estado Moderno exerça suas funções, alguns importantes estudos refinaram a compreensão do papel das burocracias, inclusive nos processos de decisão sobre políticas públicas e na sua implementação (Skocpol, 1985; Evans e Rauch, 1999; Souza, 2010). Esses estudos evidenciam tendências de politização da burocracia, especialmente a de médio escalão ou de nível intermediário (que se situa entre os políticos eleitos e os executores diretos), responsável pela gestão, bem como tendências de discricionariedade daquela que executa as ações e que estabelece relação direta com a população, a chamada "burocracia de nível da rua" (Oliveira, 2012).

A maioria dos estudos sobre burocracia, no Brasil, foca o poder Executivo federal, havendo poucos que buscam entender minimamente o que se passa nos municípios (Gouvêa, 1994; Loureiro e Abrucio, 1999; Gaetani e Heredia, 2002; Souza, 2010; Cardoso Jr., 2011; Batista, 2015), o que se faz necessário, dado o processo de descentralização de atribuições vivido no pós-Constituição Federal de 1988. Sabemos pouco sobre como a burocracia municipal é configurada, menos ainda sobre sua capacidade de ação e quase nada dos seus efeitos nos serviços. De forma geral, 
explicações sobre por que algumas burocracias estatais são mais efetivas que outras ainda estão por ser elaboradas.

É nesse sentido que se dá a contribuição deste artigo. A política de assistência social se materializa, prioritariamente, por meio da oferta de serviços no âmbito dos municípios. Assim sendo, esse tipo de política depende, fortemente, da burocracia que a implementa. Nesse sentido, a questão que se coloca é: qual o perfil da burocracia criada no nível municipal para a implementação e a gestão da política? Os municípios cujo aparato burocrático é mais estruturado, em termos weberianos, têm uma maior capacidade de implementar e gerir a assistência social? Para conseguirmos responder a essa pergunta, há um longo caminho a percorrer. Primeiro, é preciso saber quais os perfis dessa capacidade e qual a variação entre esses perfis. Há muita variação entre os municípios? Essa capacidade apresenta características regionais ou estaduais? Ou seja, alguns desses questionamentos têm uma relação espacializada? Dada a variação nos diferentes perfis municipais, pergunta-se também: há variação em sua capacidade de ação quanto a implementação e gestão da assistência social?

Trabalhamos com a hipótese de que municípios com melhor capacidade burocrática tenderiam a ser mais capazes de executar os recursos disponíveis para a assistência social. O que fizemos foi utilizar a capacidade de execução financeira como uma redução de conceitos mais difíceis de ser mensurados como implementação e gestão de serviços prestados. Com base na literatura supracitada, era de esperar que os municípios com índices mais altos dos indicadores de uma burocracia weberiana produzissem resultados melhores (ou seja, executassem mais) do que aqueles que apresentam índices mais baixos. Ou seja, a hipótese central seria de que uma maior formalidade dos vínculos empregatícios conseguisse responder mais positivamente à execução financeira. Estamos absolutamente conscientes das reduções que os indicadores têm em relação aos conceitos trabalhados, no entanto, a inexistência de dados melhores nos levou a essa opção, de forma consciente.

Para melhor entender a burocracia municipal da assistência social, utilizamos indicadores produzidos pelo MDS por meio de dados do Censo Suas de 2010 a 2014 e construímos indicadores da burocracia weberiana, relativos aos vínculos empregatícios e à educação formal, a partir de dados disponíveis na Relação Anual de Informações Sociais (Rais) de 2013 e da Pesquisa sobre os Municípios do IBGE (Munic) de 2012. Essas diferentes fontes nos fornecem dados diferenciados sobre ocupações, vínculos dos trabalhadores e sua inserção na estrutura da organização.

Dado o estágio de conhecimento de que dispomos na literatura sobre a capacidade de implementação e de gestão dos municípios e sobre as características da burocracia no âmbito da assistência social, optamos por um desenho de pesquisa descritivo que possibilitasse produzir conhecimento sobre esse fenômeno e que viesse a preceder incursões explicativas posteriores (King, Keohane e Verba, 1994; De Vauss, 2001). 
Este artigo, portanto, pretende desvendar a atual estrutura burocrática do município no que se refere à assistência social. Assim, é um estudo exploratório, mais especificamente um estudo de caso, quantitativo, pois analisa todos os municípios brasileiros, que tem como objeto os recursos humanos, que aqui representam a capacidade de implementação da política de assistência social no nível municipal e, como tal, visa a gerar hipóteses futuras sobre a gestão municipal dessa política. Utilizamos de análise espacial por partimos do pressuposto de que há padrões espaciais na variação da estrutura burocrática municipal que não estão devidamente explorados e que nos possibilitaria um melhor entendimento desse fenômeno. Dessa forma, mais do que respostas, o presente artigo induz à elaboração de perguntas, na medida em que é uma avaliação de caráter formativo.

O artigo se divide em três seções, além desta Introdução. Na primeira, "Sobre a burocracia municipal da assistência social", apresentamos alguns dados e informações acerca da capacidade de gestão dos municípios (utilizamos o termo gestão conforme utilizado pelas normas operacionais da política), tendo como referência os índices de monitoramento do MDS. Na segunda, "Sobre a capacidade de implementação e gestão", tratamos da burocracia da assistência social no âmbito municipal. Na última, "Considerações finais", algumas considerações que podem ser orientadoras para a continuidade dessa agenda de pesquisa.

\section{Sobre a burocracia municipal da assistência social}

A gestão do trabalho no Suas é regulada, principalmente, pela Norma Operacional Básica de Recursos Humanos (NOB-RH/Suas) e por resoluções do Conselho Nacional de Assistência Social. Alguns princípios foram estabelecidos por essa norma, com especial destaque para o caráter público da prestação desses serviços, apontando para a importância da existência de um quadro de servidores públicos qualificados, admitidos por concurso público, em quantidade suficiente para cada nível de governo e condições de gestão. Nesse sentido, a gestão do trabalho deve "garantir a 'desprecarização' dos vínculos dos trabalhadores do Suas e o fim da terceirização" (Brasil, 2006, p. 19).

Essa norma estabelece equipe(s) de referência ${ }^{2}$ para as unidades públicas do Suas - os Centros de Referência de Assistência Social (Cras) e os Centros de Referência Especializados de Assistência Social (Creas). As equipes de referência são compostas por

\footnotetext{
${ }^{2}$ A equipe do Cras deve ser constituída de um coordenador (técnico de nível superior, concursado, com experiência em trabalhos comunitários e gestão de programas, projetos, serviços e benefícios socioassistenciais) e, pelo menos, dois técnicos de nível superior (um assistente social e um psicólogo, preferencialmente) e dois profissionais de nível médio, conforme número de famílias referenciadas. Para os Creas, prevê-se um coordenador e, pelo menos, um psicólogo, um assistente social, um advogado, dois profissionais de nível superior ou médio e um auxiliar administrativo. Para informações mais detalhadas, ver NOB-RH/Suas.
} 
assistentes sociais, psicólogos e advogados, podendo ainda integrá-las antropólogos, economistas domésticos, pedagogos, sociólogos, terapeutas ocupacionais e musicoterapeutas.

No que se refere especificamente à gestão do Suas, é indicado um quadro de referência de profissionais para os três níveis de governo, que preconiza que eles devam ser preferencialmente servidores efetivos, responsáveis por funções essenciais. No âmbito municipal, são abarcadas desde a função de gestão do sistema municipal de assistência social até as de coordenação e gerenciamento de áreas, como a Gestão Básica e o Fundo Municipal ${ }^{3}$. As funções de gestão devem ser ocupadas, preferencialmente, pelos seguintes profissionais: administrador, advogado, antropólogo, assistente social, contador, economista, economista doméstico, pedagogo, psicólogo, sociólogo, terapeuta ocupacional (Resolução n 17/2011, CNAS).

\section{Dos vínculos dos trabalhadores do Suas}

Para conhecer a variação e a distribuição dos trabalhadores do Suas por ocupação e por tipo de vínculo ${ }^{4}$, utilizamos três fontes de dados $^{5}$ que nos dão informações diferenciadas, mas complementares e relevantes, para a análise. Inicialmente buscamos nos dados da Rais de 2013 as três ocupações relacionadas diretamente com a assistência social: assistentes sociais, psicólogos sociais e agentes de ação social. Conforme esperado, já que a Rais traz dados dos trabalhadores formais, pudemos constatar a predominância dos assistentes sociais, em detrimento das demais ocupações ${ }^{6}$. Os psicólogos sociais aparecem em segundo lugar, e de forma dispersa, no território nacional, com concentrações nos estados da Bahia e de Mato Grosso, além de uma grande frequência em Minas Gerais, São Paulo e nos estados da região Sul.

Os Mapas 1 e 2 mostram a prevalência dos vínculos dos profissionais da assistência social, a partir das bases de dados da Rais 2013 e da Munic 2012. A Rais oferece dados sobre os vínculos formais dos trabalhadores na gestão municipal, e, nesse

\footnotetext{
3 No âmbito municipal as funções de gestão são: Gestão do Sistema Municipal de Assistência Social, Coordenação da Proteção Social Básica, Coordenação da Proteção Social Especial, Planejamento e Orçamento, Gerenciamento do Fundo Municipal de Assistência Social, Gerenciamento dos Sistemas de Informação, Monitoramento e Controle da Execução dos Serviços, Programas, Projetos e Benefícios, Monitoramento e Controle da Rede Socioassistencial, Gestão do Trabalho, Apoio às Instâncias de Deliberação.

${ }^{4}$ De acordo com Nogueira e Cardoso Jr. (2011), verifica-se a existência de vínculos diretos formais entre a administração pública e o trabalhador, quando esse último é estatutário, militar, não estatutário celetista (ou emprego público), e vínculos informais, quando há contratação temporária sem vínculo direto (como nas terceirizações).

5 Utilizamos dados da Rais, que informa apenas os dados dos vínculos formais e, portanto, em menor número; os dados da Munic/IBGE, que incorporam os trabalhadores com vínculos informais e, portanto, apresentam um maior número; e os dados do Censo Suas, informados ao MDS pelos gestores da assistência social, que também apresentam dados relacionados a formalidade e informalidade dos vínculos. ${ }^{6}$ É importante deixar claro que a Rais não permite captar outros profissionais que estejam eventualmente vinculados à assistência social (como advogados, administradores, entre outras funções), por essa base de dados não conter informações específicas do campo da assistência social.
} 
caso, apresenta uma predominância de estatutários para a maioria do território nacional. No entanto, divergindo dessa tendência, São Paulo apresenta muitos municípios cuja prevalência de vínculo é o regime CLT, o que denota uma particularidade estadual na definição dos vínculos. Quando se analisam os vínculos a partir da Munic, que incorpora dados quanto aos vínculos informais, o padrão observado em São Paulo se mantém, porém há uma forte prevalência de profissionais sem vínculo permanente (os chamados vínculos temporários) nas regiões Nordeste e Norte, em Minas Gerais, principalmente no norte do estado, e em parte no Centro-Oeste. Fato que chama a nossa atenção, dado que estas são exatamente as regiões de menor desenvolvimento econômico e que, por hipótese, demandam mais serviços de assistência social. Se considerarmos que esse tipo de vínculo temporário possa estar relacionado a uma pior prestação de serviços, o quadro de distribuição dos vínculos estaria desprivilegiando (no aspecto qualitativo) as regiões mais necessitadas.

Os Mapas 3 e 4, por sua vez, correspondem à prevalência dos vínculos profissionais relacionados aos Cras e aos Creas, conforme o Censo Suas 2013, e mostram o mesmo padrão observado para a Munic. Ressalta-se ainda que, provavelmente, a ausência de informações da Rais em Goiás pode estar associada à predominância de vínculos comissionados nesse estado, e a ausência de informações em algumas regiões do Norte e Nordeste pode estar ligada à predominância de vínculos temporários que, pela natureza informal, não constariam na Rais. 
Mapa 1

Distribuição espacial da prevalência dos vínculos dos profissionais da assistência social: Brasil, por municípios - Rais, 2013

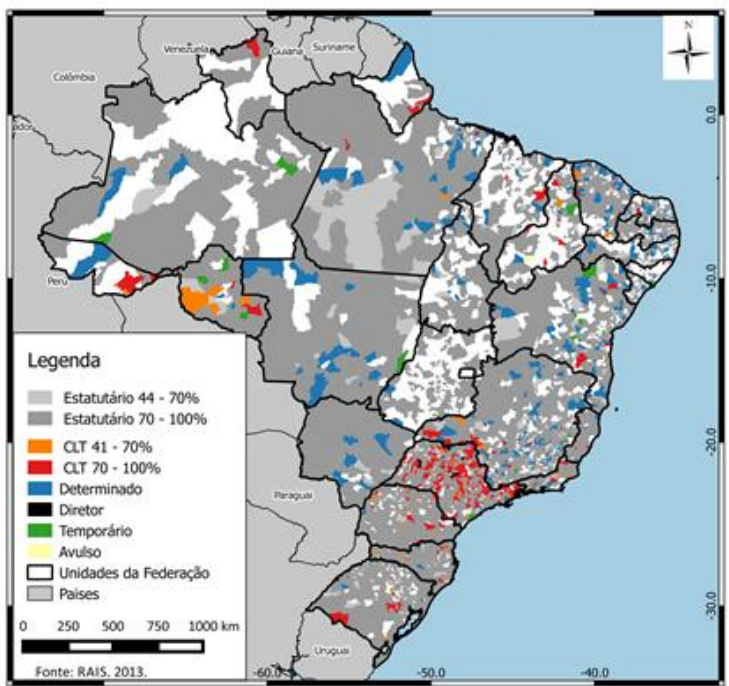

Mapa 2

Distribuição espacial da prevalência dos vínculos dos profissionais da assistência social: Brasil, por municípios - Munic, 2012

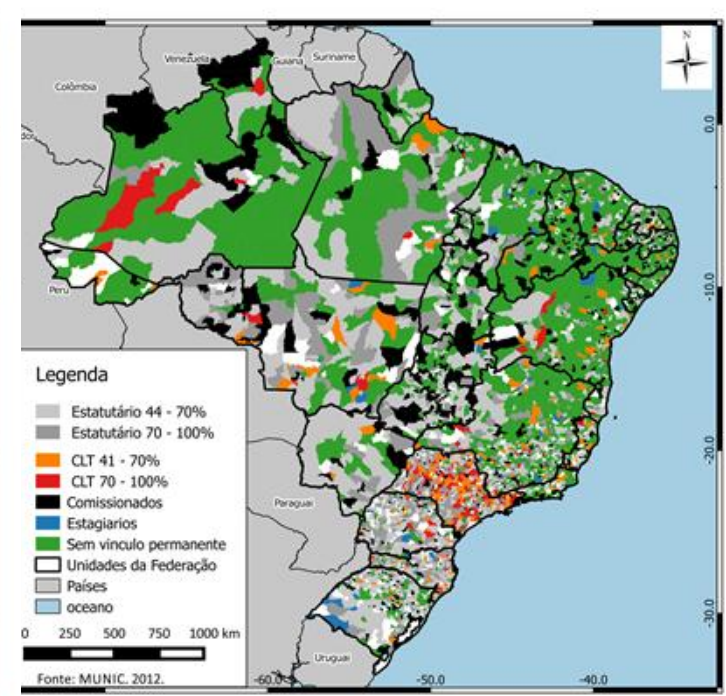

Fonte: Elaboração própria com base nos dados do Censo Suas, 2013.

Mapa 3

Distribuição espacial da prevalência dos vínculos dos profissionais da assistência social: Brasil, por municípios - Cras, Suas, 2013

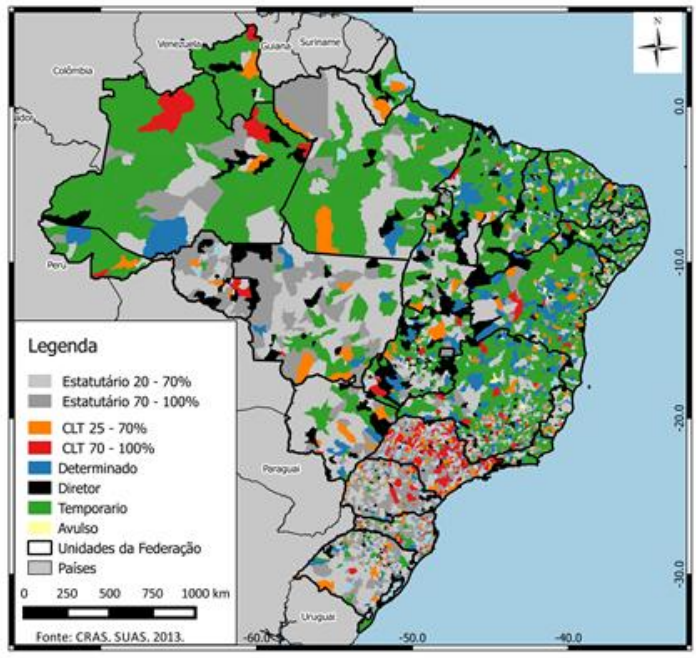

Mapa 4

Distribuição espacial da prevalência dos vínculos dos profissionais da assistência social: Brasil, por municípios - Creas, Suas, 2013

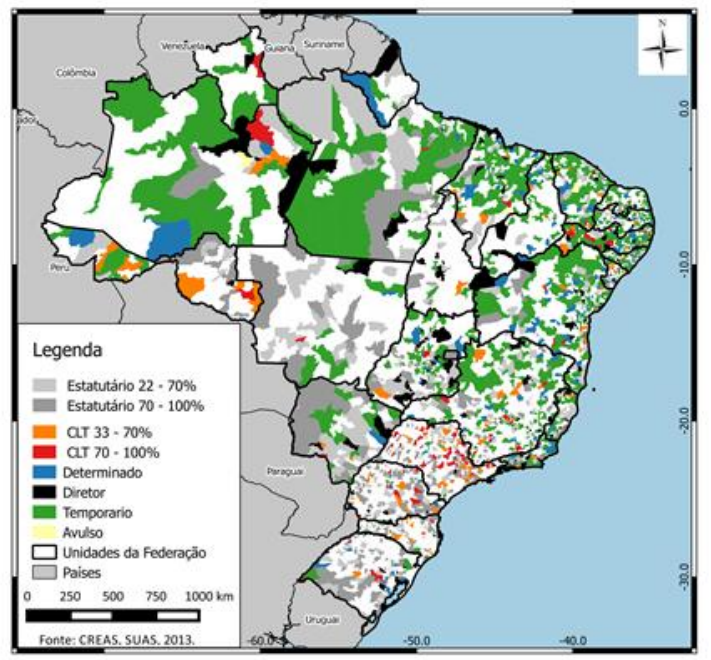

Fonte: Elaboração própria com base nos dados do Censo Suas, 2013. 


\section{Da formalidade e da espacialidade dos vínculos}

Em relação ao perfil dos vínculos profissionais na assistência social, os Mapas 3 e 4 não deixam dúvidas de que há uma relação espacial forte da informalidade que predomina em municípios das regiões Norte e Nordeste do país. Os mapas também evidenciam que há características estaduais na prevalência de determinado vínculo, sendo que São Paulo é o caso mais nítido, com predominância de contratações com vínculos CLT.

Nos Mapas 5 e 6 mostramos a distribuição espacial da proporção de profissionais da assistência social que possuem vínculos como estatutários e temporários, nos quais fica ainda mais clara a espacialidade das contratações já vista nos mapas anteriores. Observamos que o Sul do país tende à contratação de estatutários (Mapa 5) e uma forte informalidade da área a partir do norte de Minas Gerais em direção ao Nordeste e ao Norte (Mapa 6), o que só corrobora as evidências trazidas até agora pelos mapas anteriores.

Considerando que a NOB-RH estabelece um conjunto de profissões consideradas intrínsecas à assistência social, a pergunta que fica é quem, ou seja, qual profissional está numa condição ou noutra? Os Mapas 7 e 8 nos mostram a diferença entre os dados da Rais e os dados do Censo Suas para os assistentes sociais (profissionais de nível superior) e para os agentes sociais (profissionais de nível médio). Um primeiro aspecto a destacar é a própria característica das bases de dados: a Rais apresenta informações relativas a ocupações formais, ou seja, aquelas que são caracterizadas como vínculos estatutários ou de emprego com contratação formal, em que há vínculos mais estáveis, diferentemente das demais bases, nas quais estão relacionados todos os tipos de vínculos.

Ao espacializar a diferença entre as bases, encontramos três grupos de dados: aqueles municípios que são iguais a zero, que denotam não haver diferença entre os dados das duas bases, e assim aparecem em branco nos mapas; aqueles que apresentam um número positivo, que denotam que há mais profissionais declarados no Censo Suas do que na Rais, e, portanto, uma maior informalidade na contratação, que aparecem com cores quentes no mapa (amarelo, alaranjado e vermelho); e aqueles que apresentam um número negativo, denotando haver mais profissionais declarados na Rais do que no Censo Suas, o que nos relata um maior nível de formalidade, e estão no mapa em diferentes tons de azul.

Claramente vemos que os assistentes sociais apresentam vínculos com uma maior formalidade em todo o território, porém mais fortemente no sul do país. Em contrapartida, a informalidade prevalece para os agentes sociais, que provavelmente são os que engrossam a cor verde, espraiada no Mapa 3. Uma possível explicação para esses dados pode estar no fato de que a profissão de assistente social é regulamentada e os profissionais e seus empregadores são fiscalizados pelo conjunto de conselhos regionais 
da categoria. No entanto, essa regra não garante uma total formalidade dos vínculos desses profissionais no Maranhão, no Piauí e em Goiás, denotando políticas estaduais distintas nesses lugares.

Mapa 5

Distribuição espacial da proporção de profissionais da assistência social estatutários: Brasil, por municípios Cras, Suas, 2013

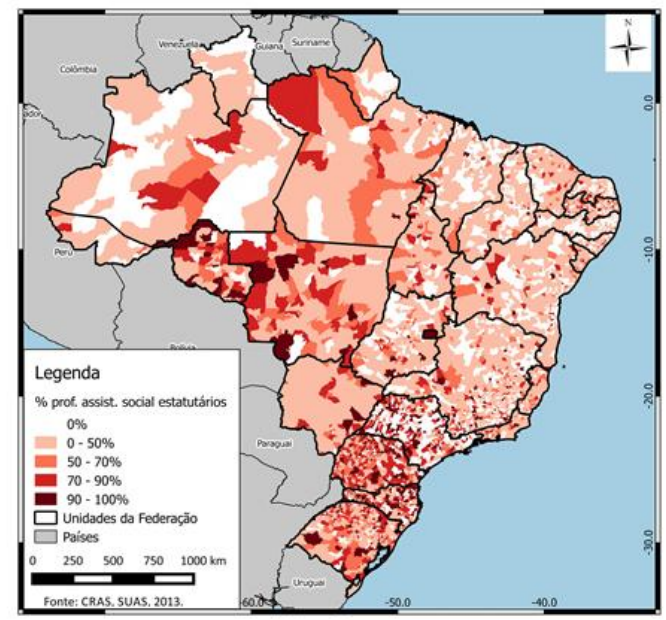

Mapa 7

Distribuição espacial da diferença dos assistentes sociais entre Rais e Suas:

Brasil, por municípios - 2013

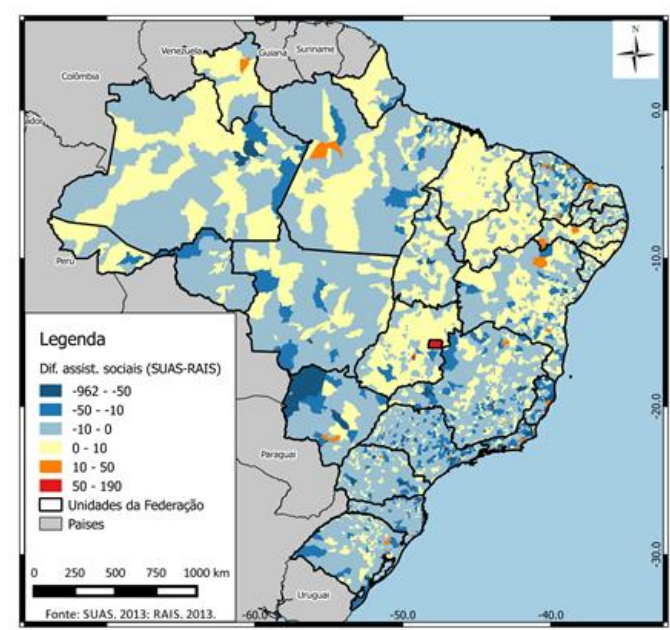

Mapa 6

Distribuição espacial da proporção de profissionais da assistência social temporários: Brasil, por municípios Cras, Suas, 2013

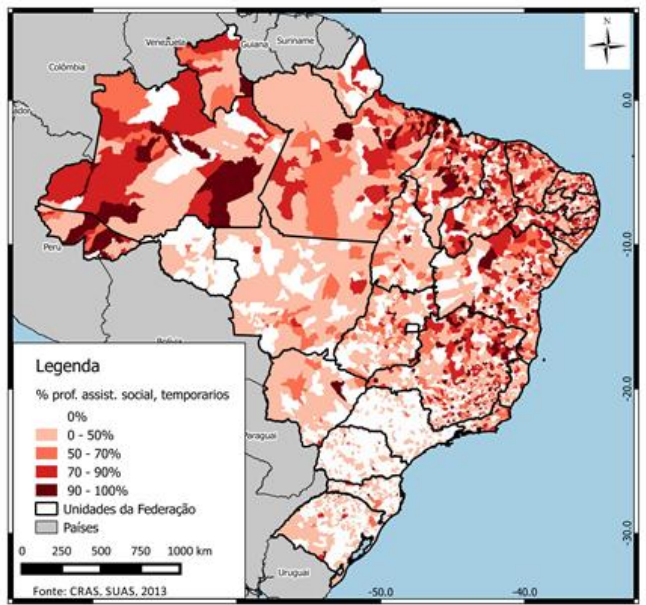

Mapa 8

Distribuição espacial da diferença dos agentes sociais entre Rais e Suas:

Brasil, por municípios - 2013

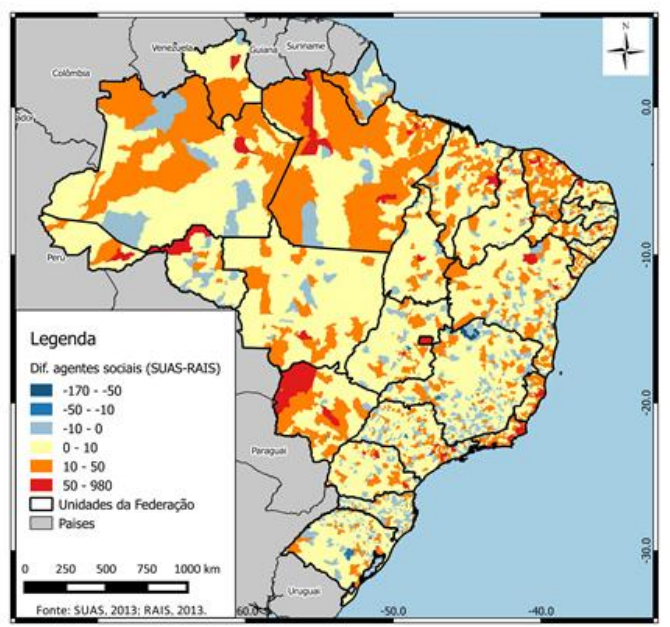

Fonte: Elaboração própria com base nos dados do Censo Suas, 2013. 
Da formação dos profissionais e de sua espacialidade

Interessante observar as evidências trazidas pelo Mapa 9, que mostra a distribuição espacial dos profissionais que possuem ensino fundamental, e juntá-las ao que mostram os Mapas de 5 a 8. Quando especializamos também os dados para ensino fundamental, Pará, Mato Grosso e Mato Grosso do Sul destacam-se pela proporção de profissionais com essa escolaridade, seguidos de Ceará, Goiás e Espírito Santo. Claramente, Nordeste, Norte e norte de Minas Gerais possuem maior proporção de profissionais com ensino médio do que os estados do Sul. O inverso disso se mostra na região Sul, já que esta apresenta maior proporção de profissionais com ensino superior em relação aos demais. Uma vez que, quando apresentamos mapas que tratam de assistentes sociais e psicólogos, estamos mostrando os profissionais com ensino superior e, quando apresentamos mapas que tratam de agentes sociais, sabemos que falamos de uma maioria com ensino médio, optamos por apresentar apenas a espacialização do profissional com ensino fundamental.

\section{Mapa 9 \\ Distribuição espacial da proporção de profissionais da assistência social com ensino fundamental: Brasil, por municípios - Suas, 2013}

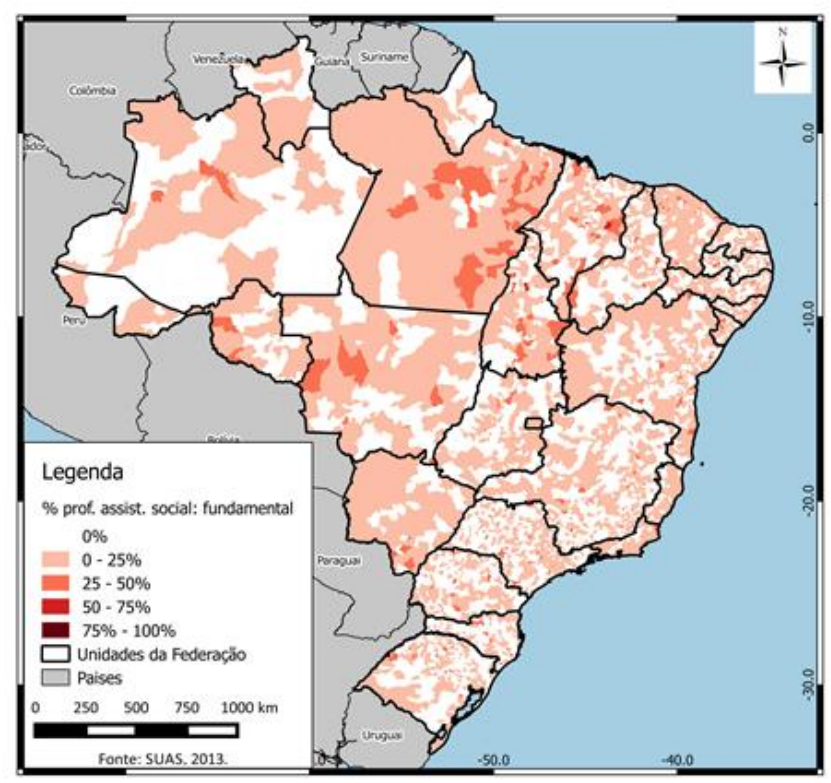

Fonte: Elaboração própria com base nos dados do Censo Suas, 2013. 


\section{Sobre a capacidade de implementação e gestão}

Ao associar capacidade de implementação e gestão à capacidade de execução financeira, é importante lembrar que a assistência social é cofinanciada pelos três entes da Federação, ou seja, ela obrigatoriamente conta com recursos municipais, estaduais e federais, que devem estar depositados e ser movimentados nos Fundos Municipais de Assistência Social, cuja responsabilidade de gestão é do município. O cofinanciamento federal tem sido sistematicamente regulado, com base em critérios acordados entre os gestores na Comissão Intergestores Tripartite (CIT), que passaram a incluir dados sobre a implementação da política no âmbito municipal.

No processo de implantação do Suas, o MDS desenvolveu indicadores que permitem monitorar os municípios, com destaque para o Índice de Desenvolvimento do Centro de Referência de Assistência Social (IDCras) e o Índice de Gestão Descentralizada do Sistema Único de Assistência Social (IGD-Suas). O IDCras agrega conhecimento sobre quatro dimensões do funcionamento dos Centros de Referência da Assistência Social (Cras): os horários de funcionamento, a estrutura física, as atividades desenvolvidas e os recursos humanos. Os Cras são equipamentos públicos que ofertam os serviços e benefícios da Proteção Social Básica, cujo funcionamento é de responsabilidade municipal. Já o IGD-Suas é constituído do próprio IDCras e da Taxa de Execução Financeira Ajustada do Fundo de Assistência Social do município ou do Distrito Federal. Essa taxa demonstra a capacidade do município de executar os recursos federais disponíveis nos Fundos Municipais. Esses índices sintéticos cumprem um papel importante para classificações e rastreamento de processos.

Dado que nosso conceito central é "capacidade de implementação e gestão do município", é necessário realizar uma reflexão sobre quais devem ser os indicadores que validem esse conceito de referência. Das dimensões mensuradas pelo IDCras, escolhemos focar nos recursos humanos e em atividades realizadas que, juntas, podem nos ajudar a validar inferências sobre a capacidade de implementação e gestão municipal.

A construção dos processos de monitoramento e avaliação da política de assistência social é recente e os ajustes nos instrumentos de coleta desses dados e mesmo na consolidação dos indicadores que melhor expressam o desenvolvimento da política fazem com que poucos indicadores estejam disponíveis para todos os municípios brasileiros. Há que considerar que os dados utilizados na composição do IDCras são fornecidos pelos próprios municípios ao MDS e servem como base de cálculo para o financiamento federal, portanto podem conter distorções. No entanto, sua composição contém dados que consideramos relevantes para nossa análise para quase todos os municípios brasileiros.

Entretanto, o foco central será a taxa de execução, uma vez que consideramos ser essa a medida mais confiável do que se passa no nível da gestão municipal. Primeiro, 
porque os municípios não têm incentivos para falseá-la. Segundo, porque em tempos de crise fiscal ninguém deixa de executar dinheiro em caixa por capricho, mas por "algum" outro motivo externo ou interno. Permitimo-nos inferir que esse é, portanto, um indicador forte de capacidade de implementação e gestão, mesmo que indireto. A taxa de execução nos indica, portanto, a dificuldade na "capacidade de implementação" da política pública em questão ou, de forma mais ampla, na própria capacidade de gestão, mesmo que seja apenas uma das dimensões possíveis desse fenômeno.

Essa taxa é a proporção do montante gasto pelo município em relação ao total de recursos repassados pelo MDS para execução dos serviços. Ou seja, trata-se de verba específica para fins de serviços da assistência social, transferida fundo a fundo do MDS para os municípios. Uma redução conceitual enorme, mas que garante a validade de nossas inferências, na medida em que parte do pressuposto de que não há governante que não queira e que não irá executar uma verba cujos serviços serão vistos como entrega de sua gestão. Quando aquele não o faz, assumimos que isso ocorre por limites burocráticos ou técnicos.

\section{Do IGD-Suas - análise espacial}

O IGD-Suas visa a acompanhar e aferir a qualidade da gestão descentralizada dos serviços, programas, projetos e benefícios socioassistenciais, bem como das ações de coordenação, monitoramento e avaliação do respectivo Suas. O índice varia de 0 (zero) a 1 (um), sendo este o melhor nível, e quanto mais próximo de 1 maior será o valor mensal a ser repassado para os estados e municípios pelo governo federal. Para esse cálculo são utilizados os dados informados pelos municípios no Censo Suas referentes ao ano fiscal anterior ao período que se inicia o repasse (contado a partir de julho, para que seja possível contabilizar corretamente a execução financeira). Por exemplo, dados do Censo Suas de 2010 foram utilizados para os repasses que se iniciaram em julho de 2012.

O Mapa 10 permite observar a distribuição espacial do IGD-Suas de 2014 referente ao ano de 2012. Numa perspectiva temporal feita em testes não apresentados, verificamos a melhora do indicador de 2014 em relação ao de 2012 (ano-base 2010). Um exemplo dessa melhoria decorre do aumento do número de municípios que alcançaram o "topo" do indicador, que pode ser visto nos Gráficos de 1 a 8. No IGD-Suas de 2012, por exemplo, 65 municípios apresentaram o nível máximo (dentre os quais $32 \%$ pertenciam à região Nordeste), enquanto no IGD-Suas de 2014, 178 municípios alcançaram o máximo do índice (sendo $24 \%$ pertencentes ao Nordeste).

A observação do Mapa 10 nos permite inferir que a região Nordeste tem índices mais altos e, portanto, melhores, do que as regiões Sudeste e Sul, conformando um padrão regional distinto. No entanto, também se verifica a diminuição da proporção de municípios nordestinos (em relação ao total de municípios brasileiros) que alcançaram o 
nível "1". Assim, a análise dos dois momentos permite dizer que, se inicialmente o índice mostrou patamares um pouco mais elevados no Nordeste brasileiro, em um segundo momento podemos observar que o IGD-Suas tem melhorado no Brasil de uma maneira geral, indicado pelo aumento da média nacional do IDG-Suas, de 65,6\% para 70\%, respectivamente a 2012 e 2014, contra um aumento mais "modesto" da região Nordeste, de $70,3 \%$ para $73,8 \%$, no mesmo período. Mesmo assim ainda deve ser destacada a manutenção do nível do IGD-Suas nordestino acima da média do país.

\section{Mapa 10 \\ Distribuição espacial do IGD-Suas: Brasil, por municípios - 2014}

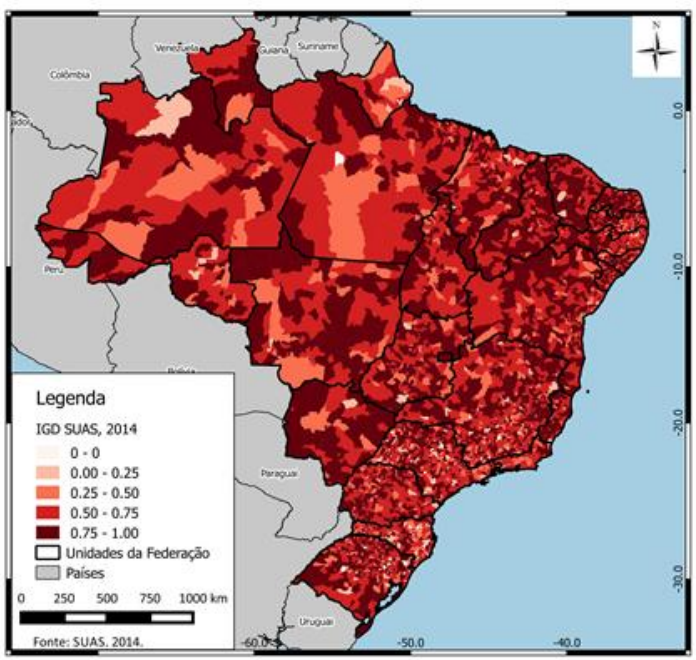

Mapa 11

\section{Autocorrelação espacial do IGD-Suas: Brasil, por municípios - 2014}

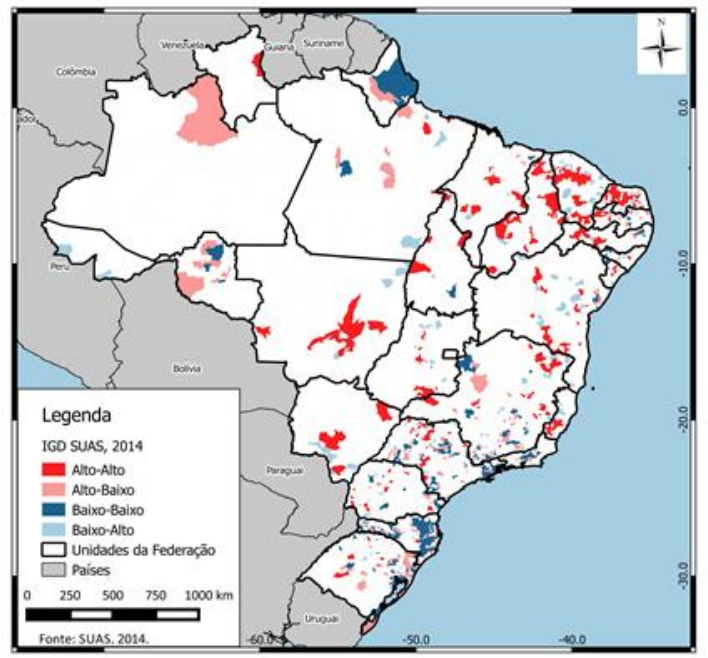

Fonte: Elaboração propria com base nos dados do Suas 2012 e 2014.

O Mapa 11 nos mostra a autocorrelação espacial do IGD-Suas 2014, e por meio dele podemos observar também um comportamento regional distinto ${ }^{7}$. Podemos ver uma relação alta-alta predominante no Nordeste do país e em alguns lugares do CentroOeste, enquanto nos estados do Sul predominam relações baixa-baixa, em especial em Santa Catarina, o que reforça a desigualdade regional desse indicador já apresentado no Mapa 10.

Mas como se comportam os elementos internos ao IGD-Suas? Como eles podem ser usados para nos ajudar a entender melhor o que se passa nos municípios? É o que vemos a seguir.

\footnotetext{
7 Os municípios em vermelho têm correlação de vizinhança alto-alto, ou seja, o município em vermelho tem um alto IGD-Suas e seus vizinhos também possuem um alto valor. Já os municípios em azul-escuro indicam o contrário: eles têm um baixo IGD-Suas e seus vizinhos também. Os municípios coloridos de rosa possuem um alto IGD-Suas, mas seus vizinhos possuem índice baixo, destacando-se positivamente em relação aos seus vizinhos. Já aqueles municípios coloridos de azul-claro possuem um baixo IGD-Suas, mas possuem vizinhos com alto índice, ou seja, eles têm desempenhos piores do que seus vizinhos.
} 
Do IDCras

Antes de entrar nas duas dimensões que nos interessam de recursos humanos e de atividades realizadas, cabe a análise breve das quatro dimensões do IDCras para mapear o contexto a partir do qual trabalhamos. A Tabela 1, de frequência simples, mostra que $79,1 \%$ dos Cras declaram ter um horário de funcionamento que é suficiente para o exigido, enquanto $18,4 \%$ dizem que funcionam mais do que o horário-padrão, considerado suficiente. Outros $74,2 \%$ dos Cras consideram que têm um espaço suficiente $(51,5 \%)$ ou superior ao exigido pela NOB-Suas. Em relação aos recursos humanos, $20,6 \%$ dos Cras declaram ter um número insuficiente de recursos humanos, o que consideramos um número alto pela importância do indicador. Entretanto, chama atenção que, apesar desse indicador relativo a recursos humanos, 86,7\% dos Cras têm um padrão de atividades superior ao esperado.

Tabela 1

Frequência das dimensões do IDCras - 2012

\begin{tabular}{|l|c|c|c|c|c|c|c|c|}
\hline & \multicolumn{2}{|c|}{$\begin{array}{c}\text { Horário de } \\
\text { funcionamento }\end{array}$} & \multicolumn{2}{c|}{$\begin{array}{c}\text { Estrutura } \\
\text { física }\end{array}$} & \multicolumn{2}{c|}{$\begin{array}{c}\text { Atividades } \\
\text { realizadas }\end{array}$} & \multicolumn{2}{c|}{$\begin{array}{c}\text { Recursos } \\
\text { humanos }\end{array}$} \\
\hline & $\mathbf{N}$ & $\mathbf{\%}$ & $\mathbf{N}$ & $\mathbf{\%}$ & $\mathbf{N}$ & $\mathbf{\%}$ & $\mathbf{N}$ & $\%$ \\
\hline Insuficiente & $\mathbf{2 3}$ &, 3 & $\mathbf{1 5 0 7}$ & 19,5 & $\mathbf{1 9 4}$ & 2,5 & $\mathbf{1 5 9 2}$ & 20,6 \\
\hline Regular & $\mathbf{1 7 3}$ & 2,2 & $\mathbf{4 8 8}$ & 6,3 & $\mathbf{7 7 9}$ & 10,1 & $\mathbf{7 6 3}$ & 9,9 \\
\hline Suficiente & $\mathbf{6 1 0 9}$ & 79,1 & $\mathbf{3 9 7 8}$ & 51,5 & $\mathbf{5 3}$ &, 7 & $\mathbf{3 8 9 5}$ & 50,4 \\
\hline Superior & $\mathbf{1 4 2 0}$ & 18,4 & $\mathbf{1 7 5 2}$ & 22,7 & $\mathbf{6 6 9 9}$ & 86,7 & $\mathbf{1 4 7 5}$ & 19,1 \\
\hline Total de Cras & $\mathbf{7 7 2 5}$ & 100,0 & $\mathbf{7 7 2 5}$ & 100,0 & $\mathbf{7 7 2 5}$ & 100,0 & $\mathbf{7 7 2 5}$ & 100,0 \\
\hline
\end{tabular}

Fonte: Elaboração própria com base nos dados do IDCras-2012.

Dessa forma, é interessante observar como esses dois últimos indicadores se comportam juntos:

Tabela 2

Recursos humanos e atividades realizadas, IDCras - 2012

\begin{tabular}{|c|c|c|c|c|c|c|c|c|}
\hline \multirow{3}{*}{$\begin{array}{l}\text { Dimensão atividades } \\
\text { realizadas }\end{array}$} & \multicolumn{8}{|c|}{ Dimensão recursos humanos } \\
\hline & \multicolumn{2}{|c|}{ Insuficiente } & \multicolumn{2}{|c|}{ Regular } & \multicolumn{2}{|c|}{ Suficiente } & \multicolumn{2}{|c|}{ Superior } \\
\hline & $\mathbf{N}$ & $\%$ & $\mathbf{N}$ & $\%$ & $\mathbf{N}$ & $\%$ & N & $\%$ \\
\hline Insuficiente & 70 & 4,4 & 16 & 2,1 & 86 & 2,2 & 22 & 1,5 \\
\hline Regular & 206 & 12,9 & 72 & 9,4 & 387 & 9,9 & 114 & 7,7 \\
\hline Suficiente & 20 & 13 & 12 & 1,6 & 15 &, 4 & 6 &, 4 \\
\hline Superior & 1296 & 81,4 & 663 & 86,9 & 3407 & 87,5 & 1333 & 90,4 \\
\hline
\end{tabular}

Fonte: Elaboração própria com base nos dados do IDCras-2012. 
A análise nos leva a enfatizar dois aspectos importantes: um, aqueles municípios que, mesmo declarando recursos humanos insuficientes ou regulares $(30,5 \%)$, apresentam atividades regulares suficientes ou superiores ao esperado. Outro, na perspectiva inversa, aqueles municípios que possuem classificação suficiente e superior no que diz respeito aos recursos humanos, mas apresentam atividades realizadas insuficientes. A pergunta é: por que alguns, mesmo com poucos recursos humanos, conseguem realizar suas atividades e outros, com recursos satisfatórios, não conseguem realizá-las?

Eles nos obrigam a perguntar: o que faz com que ocorra uma produtividade declarada tão grande, superior aos recursos instalados? Ou eles mostram problemas na declaração dos dados ou mostram o tamanho da demanda existente por serviços dessa natureza. Caso seja a segunda opção, é possível inferir que serviços têm sido prestados na tentativa de atender à demanda, independentemente das condições relativas aos recursos humanos disponíveis, o que, com certeza, coloca em risco a qualidade dos serviços que chegam à população. Para saber responder a esses questionamentos certamente serão necessários outros dados para além destes.

A análise permite observar um contrassenso: enquanto a distribuição das atividades realizadas se apresenta como suficiente ou superior em praticamente todo o país, a distribuição espacial dos recursos humanos guarda diferenças. Regiões reconhecidamente mais "desenvolvidas" (como o sul de Minas Gerais, os estados de São Paulo, Santa Catarina e Rio Grande do Sul), onde se poderia supor, a princípio, que houvesse uma menor demanda por serviços de assistência social em relação a regiões ditas menos desenvolvidas do ponto de vista econômico e social, como Norte e Nordeste, apresentam maior proporção de municípios com recursos humanos insuficientes ou regulares. Essa distribuição pode estar associada a problemas na declaração, como já mencionado, mas também pode estar relacionada com políticas públicas que priorizem, de fato, as regiões mais pobres, ou mesmo à percepção das burocracias do que é razoável ser considerado em cada caso.

Sobre essa penúltima possibilidade, quando se analisa o interior dos estados de Pernambuco e da Paraíba, por exemplo, os recursos humanos são declarados como suficientes justamente nas porções mais interioranas dessas unidades da Federação, que, por sua vez, são regiões marcadas pelo clima semiárido, sendo notadamente áreas menos desenvolvidas e com uma possível maior demanda por assistência social. Em contraponto, a região leste dos estados, marcada pelo agreste (menos seco) e mais desenvolvida em relação ao oeste, apresenta uma elevada proporção de municípios que declaram recursos humanos insuficientes. Contudo, é importante destacar que as afirmativas acima são meras hipóteses, pois não há um padrão espacial perfeitamente homogêneo, que permita transformar essas tendências e possibilidades observadas em análises conclusivas. 
Da taxa de execução

Como já dito, dentre aqueles indicadores disponíveis, julgamos que a taxa de execução dos recursos federais é a que melhor expressa a capacidade dos municípios de executarem a política de assistência social no seu âmbito de atuação. Além de serem dados confiáveis e auditáveis, demonstram em que medida a estrutura administrativa municipal está estruturada e com habilidade para planejar, orçar e executar os recursos, considerados essenciais para a entrega dos serviços e benefícios.

A primeira pergunta é: qual a variação da taxa de execução financeira nos três anos para os quais ela foi calculada? O Gráfico 1 , boxplot ${ }^{8}$, nos mostra a variação total dessa taxa, sendo que cada caixa corresponde à taxa de execução de um ano específico (2010, 2011 e 2012). Observa-se que há uma variação muito grande entre os municípios, ainda que, de modo geral, executa-se bem o recurso repassado. No entanto, do ponto de vista da gestão, é preocupante a grande variação dos $25 \%$ inferiores. Há claramente uma melhoria da taxa para o ano de 2012, mas, ainda assim, há centenas de municípios que não conseguem executar. Qual o perfil desses municípios?

\footnotetext{
${ }^{8}$ O boxplot nos dá informações por quartis. A linha do meio de cada caixa é a mediana, ou seja, ela corta os municípios na metade, $50 \%$ para baixo, $50 \%$ para cima dessa linha. O primeiro quartil está da extremidade superior para baixo, o segundo quartil corresponde à primeira parte da caixinha, o terceiro quartil é a parte debaixo da linha mediana e o quarto quartil é a linha abaixo da caixa. Os pontos abaixo dessa linha são as exceções (outliers e pontos extremos nessa distribuição).
} 


\section{Gráfico 1}

Taxa de execução financeira do IGD-Suas para todos os municípios, por ano

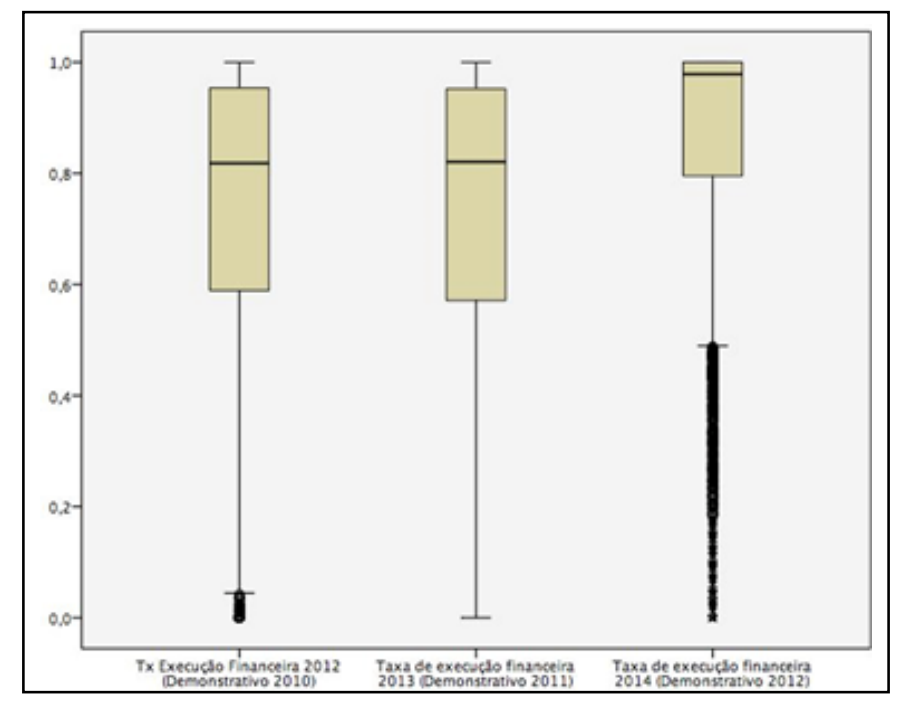

Fonte: Elaboração própria com base nos dados do Demonstrativo Sintético Anual da Execução Físico-Financeira acessado em 23 de março de 2015 no site do MDS.

Uma segunda pergunta: como é a distribuição espacial dessa taxa? Os Mapas 12 e 13 permitem dizer que houve uma melhora substantiva da execução financeira entre os anos de 2010 e de 2012, com um protagonismo claro da capacidade de execução dos estados nordestinos sobre os demais. Se pensarmos que as regiões Sul e Sudeste têm maior mercado de trabalho e desenvolvimento econômico e social, poderíamos supor uma maior capacidade burocrática municipal como reflexo disso. Havendo maior capacidade burocrática municipal, esperar-se-ia melhor capacidade de execução. No entanto, esse resultado não corrobora esse raciocínio. Ao contrário, ao que nos parece, as regiões com maior necessidade e demanda por serviços e benefícios da assistência social criam suas estratégias para executar de forma mais eficiente os recursos repassados pelo governo federal.

Ou seja, os dados nos permitem inferir que a melhor taxa de execução não está nos municípios mais ricos, supostamente com melhor capacidade de implementação e de gestão, mas onde mais se necessita do recurso público que garante a proteção social. Enquanto a taxa de execução no Brasil aumentou de 72,6\% para 84,7\% entre 2010 e 2012, a região Nordeste observou $82,6 \%$ e $93,2 \%$ no mesmo período. Embora o crescimento percentual do Nordeste tenha sido um pouco menor que o crescimento da média nacional, o aumento de 10,6 pontos percentuais é surpreendente, dado que o crescimento de uma taxa se torna tão mais difícil quanto mais próxima se encontra do máximo. Contudo, o crescimento ocorreu em todo o país, dado que, no período 
observado, a proporção de municípios com taxa de execução acima de $75 \%$ subiu de $59,6 \%$ para 78,7\%; sendo interessante ressaltar nos Mapas 12 e 13 que as regiões Nordeste, Norte, Centro-Oeste e também o norte de Minas Gerais praticamente alcançaram a quase totalidade de municípios pertencentes ao quartil mais elevado (75\%) da taxa de execução:

Mapa 12

Distribuição espacial da taxa de execução financeira: Brasil, por municípios - IGD-Suas, 2010

\section{Mapa 13}

Distribuição espacial da taxa de execução financeira: Brasil, por municípios - IGD-Suas, 2012
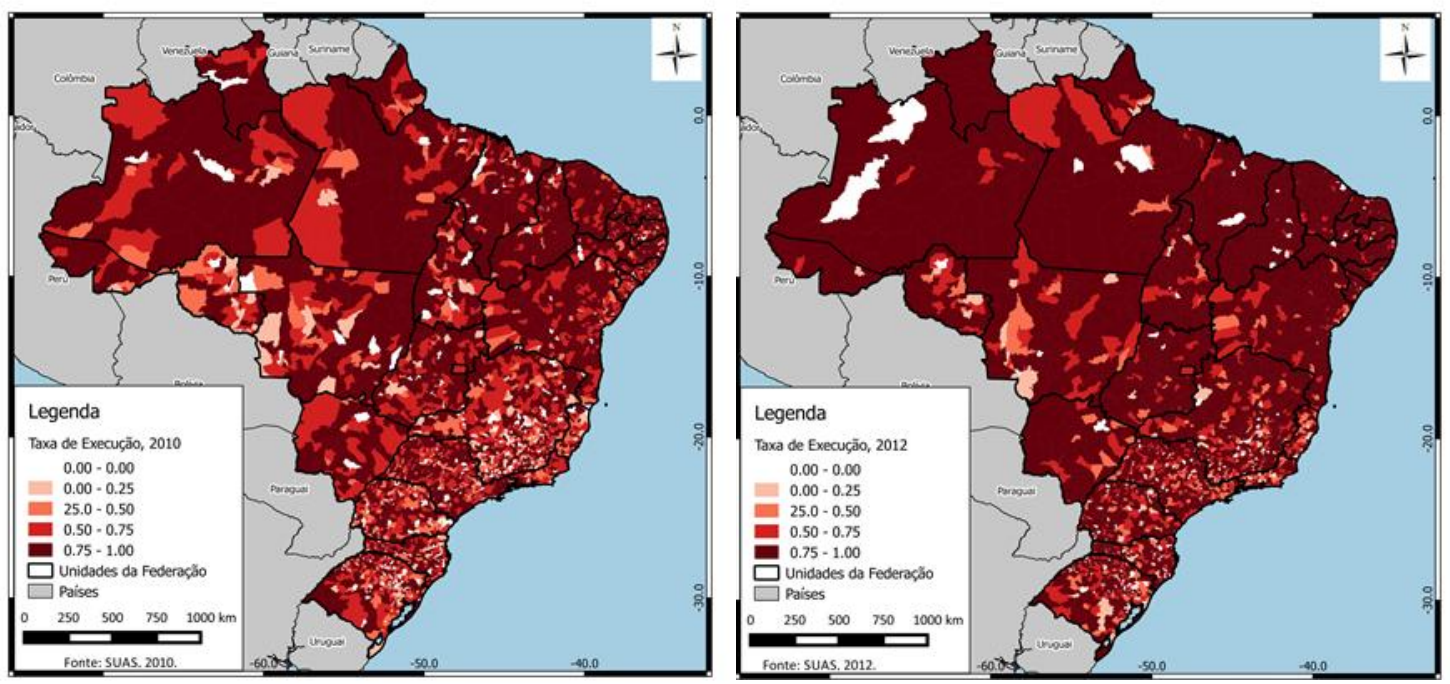

Fonte: Elaboração própria com base nos dados do Censo Suas 2010 e 2012.

Vejamos o mesmo dado apresentado de outra forma para melhor compreensão. Os Gráficos de 2 a 8 nos dão o intervalo de confiança da distribuição espacial da taxa de execução financeira. Deles se depreendem três informações principais: houve uma melhoria real da distribuição no tempo, uma vez que a execução de 2012 foi substantivamente mais alta do que nos demais anos. Provavelmente os municípios aprenderam a executar no processo em função dos incentivos criados pelo MDS, o que a literatura chama de aprendizado institucional (Sátyro e Cunha, 2014). Também se evidencia a maior eficiência da execução das regiões Nordeste e Norte em relação à do Sudeste e Sul. No entanto, a partir desses gráficos fica clara a variação intrarregional e, mais ainda, no interior de cada estado também, com destaque para Roraima e Amapá. 
Gráfico $\mathbf{2}^{9}$

Barras de erro ${ }^{10}$ - Taxa de execução financeira

para todos os municípios, por ano e por estados

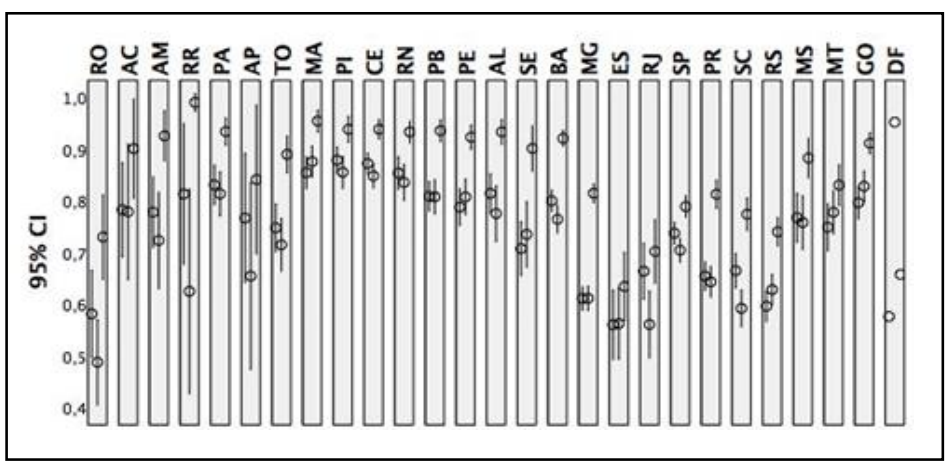

Gráfico 3

Distribuição da taxa de execução nos estados da região Norte, por ano

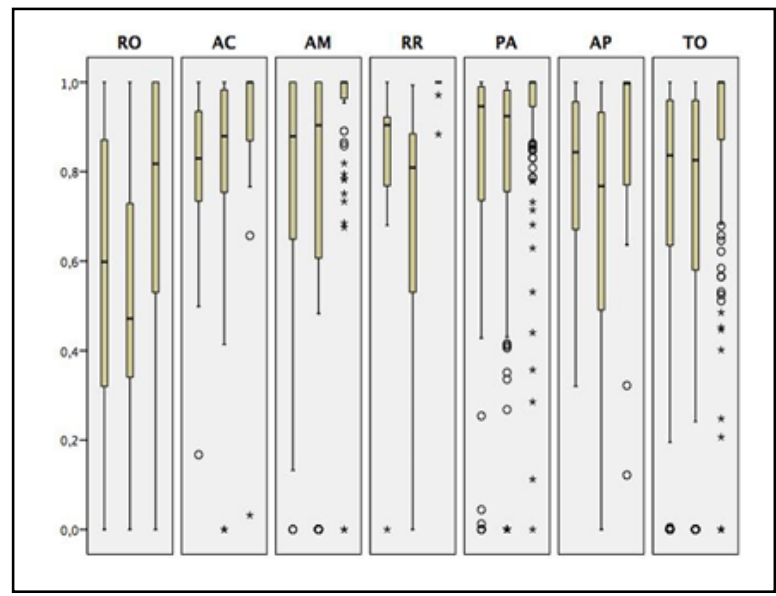

9 Observação para os Gráficos de 2 a 8: Os três dados apresentados para cada estado referem-se respectivamente às Taxas de Execução Financeira dos anos 2012, 2013 e 2014.

${ }^{10}$ Gráfico de barras de erros plotam os intervalos de confiança e erro-padrão, ou desvios-padrão, das variáveis individuais. 
Gráfico 4

Distribuição da taxa de execução nos estados da região Nordeste, por ano

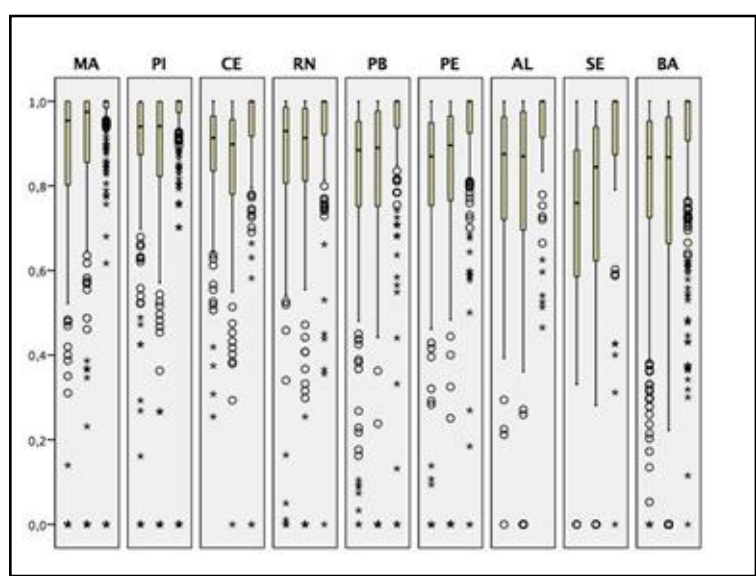

Gráfico 5

Distribuição da taxa de execução nos estados da região Sudeste,

por ano

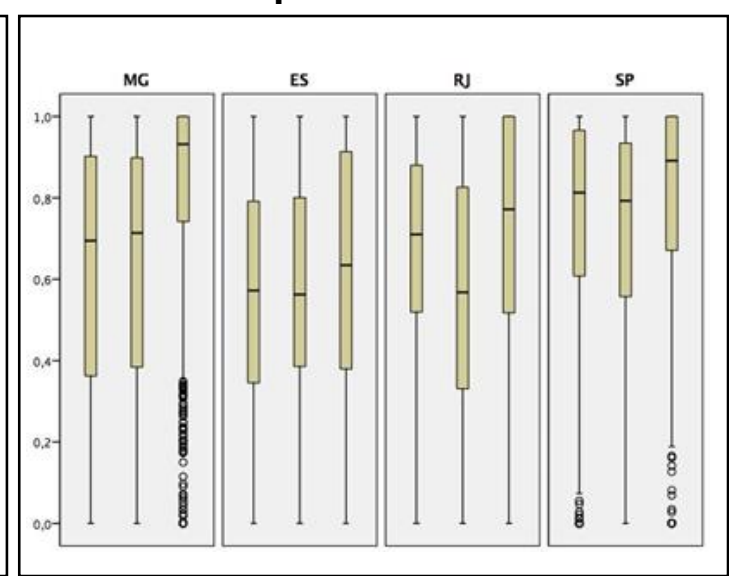

\section{Gráfico 6}

Distribuição da taxa de execução nos estados da região Sul, por ano

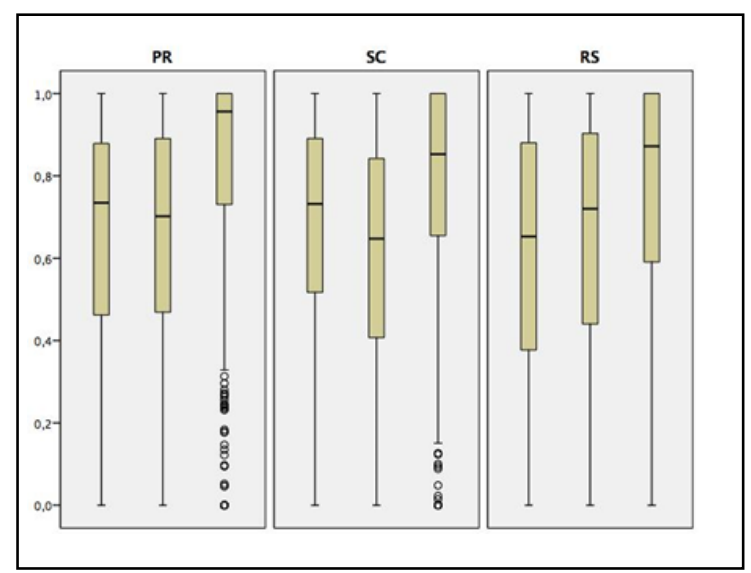

Gráfico 7

Distribuição da taxa de execução nos estados da região Centro-Oeste, por ano

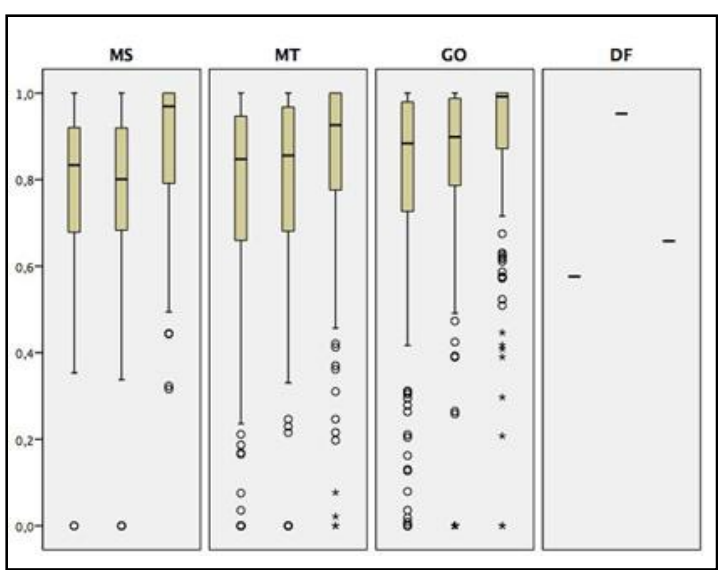

Fonte: Gráficos de 2 a 7 - Elaboração própria com base nos dados do Demonstrativo Sintético Anual da Execução Físico-Financeira, acessado em 23 de março de 2015 no site do MDS.

Ao analisarmos as regiões separadamente no boxplot, verificamos a melhoria da eficiência da execução no tempo, mas fica ainda mais enfatizada a variação interna nos 
estados, representada tanto pelos tamanhos consideráveis do quarto quartil quanto pela grande quantidade de outliers (bolinhas) e pontos extremos (estrelinhas).

Se a região Nordeste executa mais, em média, ela também apresenta uma enorme variação na capacidade dos municípios de executarem os recursos federais alocados em seus fundos municipais. Boa parte dos municípios aprendeu a executar os recursos no tempo, como pode ser visto pelo achatamento dos dois primeiros quartis no ano de 2012. No entanto, se podemos afirmar que 50\% dos municípios nordestinos executam tudo o que recebem, podemos também observar os $25 \%$ inferiores, bem como a enorme quantidade de outliers e de casos extremos em absolutamente todos os estados, inclusive aqueles em que nada foi executado.

A análise torna-se ainda mais interessante quando se observam as regiões Sudeste e Sul. Diferente do Nordeste, somente 25\% dos municípios do SE conseguiram executar todos os recursos em 2012, sendo que o Espírito Santo apresenta as menores medianas, com cerca de $60 \%$ de taxa de execução, 20 pontos percentuais a menos do que o Nordeste. Os estados do Espírito Santo e do Rio de Janeiro não apresentam casos extremos e outliers, mas isso aparece fortemente em Minas Gerais, que tem uma quantidade considerável desses casos. De forma geral, podemos afirmar que outros $25 \%$ dos municípios nessa região executaram menos da metade dos recursos repassados no ano de 2012.

O Sul tem o mesmo perfil do Sudeste: $25 \%$ dos municípios executaram tudo e outros $25 \%$ dos municípios nessa região executaram menos da metade dos recursos repassados no ano de 2012.

No Centro-Oeste, apesar de observarmos uma grande variação, os municípios se mostram um pouco menos heterogêneos do que nas demais regiões, uma vez que a linha que mostra o quarto quartil é, de forma geral, mais curta do que nos demais estados, com o piso geral em torno de $40 \%$ de execução. Entretanto, Mato Grosso e Goiás apresentam muitos casos extremos e outliers.

Os dados relacionados à taxa de execução dos recursos federais pelos municípios indicam que, em termos de medidas de tendência central, passamos de uma média alta, que variou entre 0,73 (2010), 0,72 (2011), alcançando 0,85 em 2012. Entretanto, o desvio grande indica uma amplitude também muito grande na capacidade de execução, o que nos permite inferir uma amplitude muito grande também nas capacidades de implementação e de gestão reais e não formais. Por outro lado, os dados também evidenciam que houve um aprendizado institucional de como fazer nesse período. Por fim, é importante notar que Nordeste e Norte tendem a ter indicadores melhores. 
Da taxa de execução - análise de autocorrelação espacial

O Mapa 14, de cluster, nos diz se há alguma correlação espacial que deve ser levada em consideração para entendermos a taxa de execução dos recursos federais pelos municípios brasileiros ${ }^{11}$.

Numa primeira análise fica evidenciado que as taxas de execução mais elevadas estão concentradas nas regiões Norte e Nordeste principalmente, em contraponto às regiões Sudeste e Sul. Outro aspecto bastante interessante é que os clusters de alta taxa de execução do Nordeste (de tom vermelho) localizam-se nas porções menos desenvolvidas dessa região, ou seja, nas áreas interioranas, marcadas pelo bioma do semiárido (interior dos estados do Maranhão, Piauí, Ceará, Pernambuco e Bahia). No outro extremo, os "bolsões" de baixa taxa de execução (em azul) localizam-se na região central e sul de Minas Gerais, Espírito Santo, Rio de Janeiro, o eixo (sudeste sentido noroeste) da rodovia Anhanguera no estado de São Paulo (região muito desenvolvida economicamente), além da região Sul, de um modo geral. Se o padrão regional ficou tímido quando analisamos o IGD-Suas, aqui fica nítido que onde há maior demanda se executa mais, independentemente da capacidade instalada.

\footnotetext{
${ }^{11}$ Onde não há cores não há correlação entre os vizinhos. Onde há aglomerados vermelhos significa que os municípios possuem uma alta taxa de execução assim como seus vizinhos. Do lado oposto, temos os azuisescuros que mostram a correlação de vizinhança entre municípios que executam pouco. Os municípios em azul-claro têm uma lógica invertida, apresentam baixa taxa de execução, enquanto seus vizinhos apresentam uma alta taxa. Para os de cor rosa a perspectiva é contrária: são municípios que possuem uma alta taxa de execução enquanto seus vizinhos possuem uma baixa taxa.
} 


\section{Mapa 14 \\ Autocorrelação espacial da taxa de execução: Brasil, por municípios - 2012}

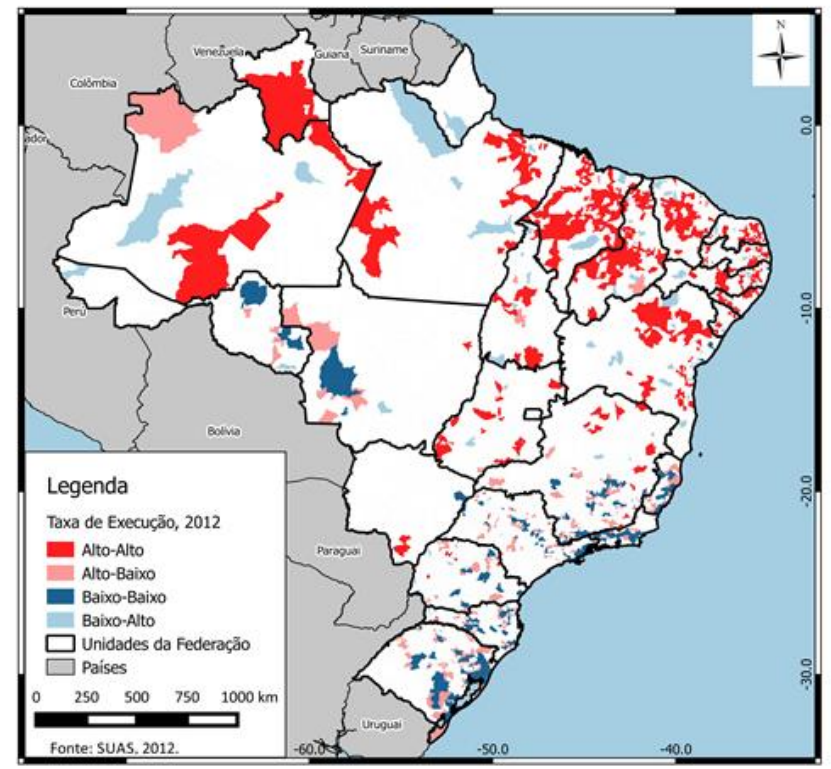

Fonte: Elaboração própria com base nos dados do Suas 2012.

Da taxa de execução - por porte de municípios

Levantamos a hipótese de que municípios com maior porte populacional tendem a ser mais bem estruturados em suas burocracias e, em decorrência, teriam maior capacidade de ser eficientes na execução dos recursos. No entanto, o Gráfico 8 nos mostra que não é bem assim. A hipótese é parcialmente refutada, pois podemos observar que, em média, tanto os municípios entre 100 mil e 500 mil habitantes quanto os com população maior que 500 mil executam menos do que os menores. Entretanto, os municípios com mais de 500 mil habitantes têm uma variação menor do que os demais, com apenas dois outliers e um caso extremo no ano de 2012.

No entanto, podemos observar que, apesar de $50 \%$ dos municípios com menos de 20 mil habitantes executarem mais de $80 \%$ dos recursos, a variação daqueles que estão abaixo da mediana é muito grande. Não há dúvidas quanto à melhoria generalizada em 2012, sendo que os municípios que ocupam o quarto quartil, ou seja, os $25 \%$ com menor execução, a apresentam acima de $40 \%$. Mas, num país com tantos municípios, a quantidade daqueles que ainda não estão executando os recursos é muito grande, o que pode ser inferido a partir da presença maciça de outliers e casos extremos que se encontram abaixo de cada caixinha para os respectivos anos e portes populacionais. 


\section{Gráfico 8 \\ Distribuição da taxa de execução de todos os municípios, por porte populacional e por ano}

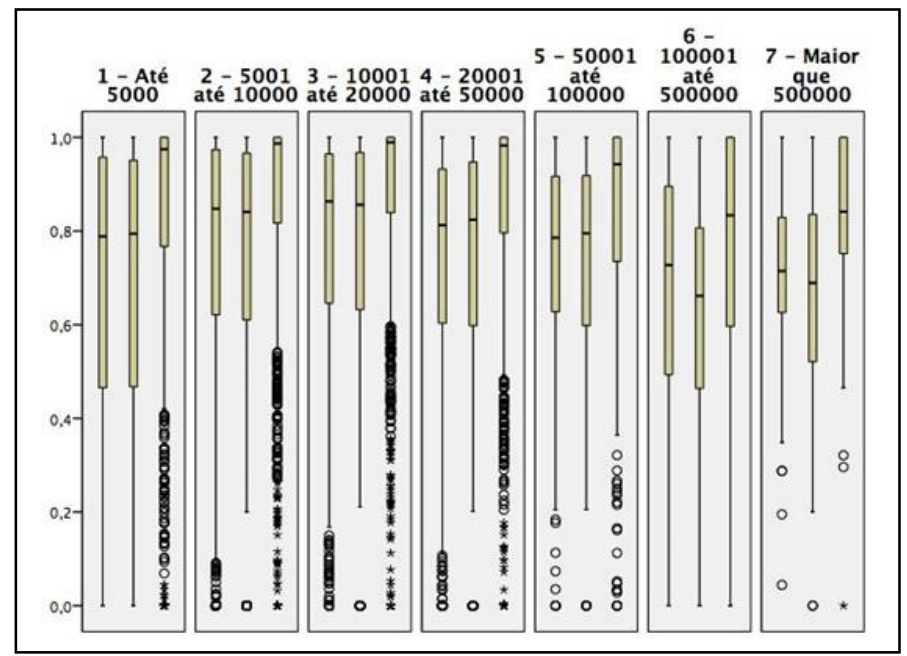

Fonte: Elaboração própria com base nos dados do Demonstrativo Sintético Anual da Execução Físico-Financeira, acessado em 23 de março de 2015 no site do MDS.

Da relação entre taxa de execução e vínculos empregatícios

A literatura sobre burocracia considera que funcionários recrutados por mérito (concursos) e com previsibilidade de carreiras de longo prazo (estabilidade) têm mais competências, habilidades e incentivos para levar a termo as funções do Estado. No nosso caso, os chamados estatutários, que se enquadram nesse tipo, teriam mais e melhores condições de implementação da política, o que nos permite supor que a um maior número de estatuários corresponderia melhor capacidade de implementação e de gestão, ou taxa de execução (nosso indicador).

A partir do cenário encontrado, foram filtrados os municípios que executam menos de $40 \%$ dos recursos federais que recebem. Um corte, naturalmente, arbitrário, mas que nos permite verificar aqueles que, mesmo respondendo positivamente às dimensões da gestão no IDCras, por exemplo, não conseguem executar os recursos. Construímos gráficos de dispersão (Gráficos 9 e 10) das duas medidas, ou seja, só dos municípios com menor taxa de execução para o demonstrativo de 2010 (ano de 2012) e para o de 2012 (ano de 2014). O resultado é desconcertante: apesar de observarmos uma diminuição sensível de casos entre os dois anos, não há nenhuma correlação entre ter uma baixa proporção de estatutários na assistência social e a capacidade de execução. A nuvem de dispersão capta a todos igualmente. 


\section{Gráfico 9}

Dispersão da taxa de execução para municípios com $40 \%$ ou menos de execução em relação à proporção de estatuários, em 2012

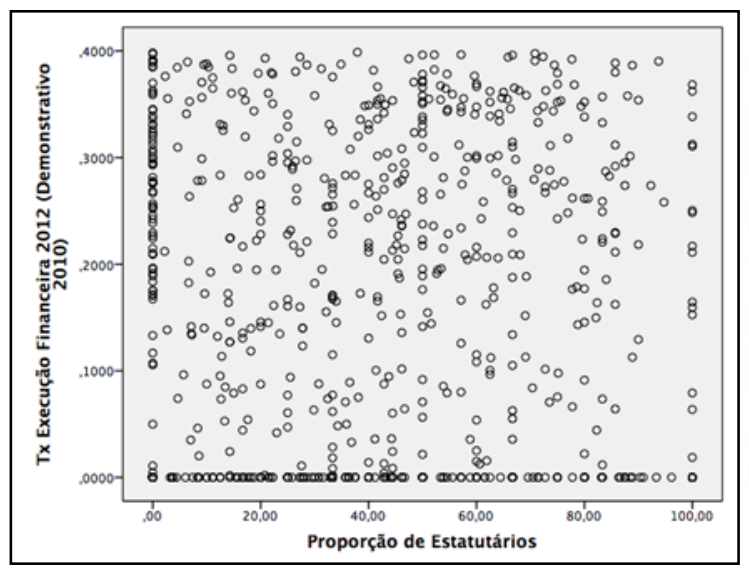

Gráfico 11

Dispersão da taxa de execução para municípios com $40 \%$ ou menos de execução em relação à proporção de sem vínculos, em 2012

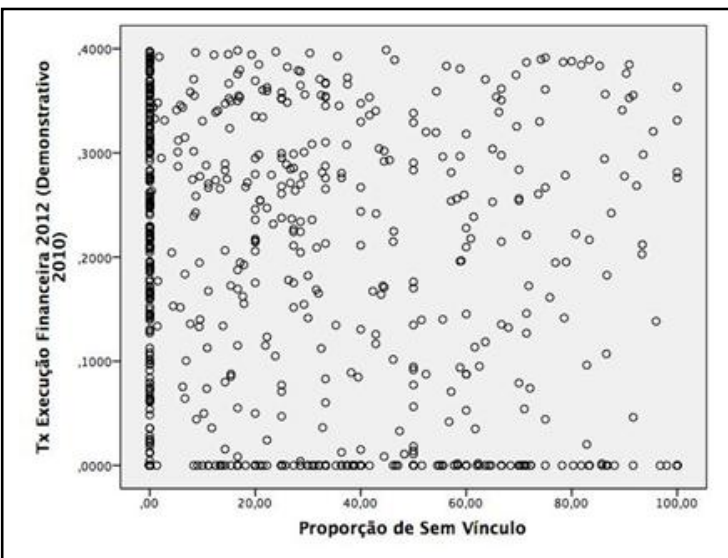

Gráfico 10

Dispersão da taxa de execução para municípios com $40 \%$ ou menos de execução em relação à proporção de estatuários, em 2014

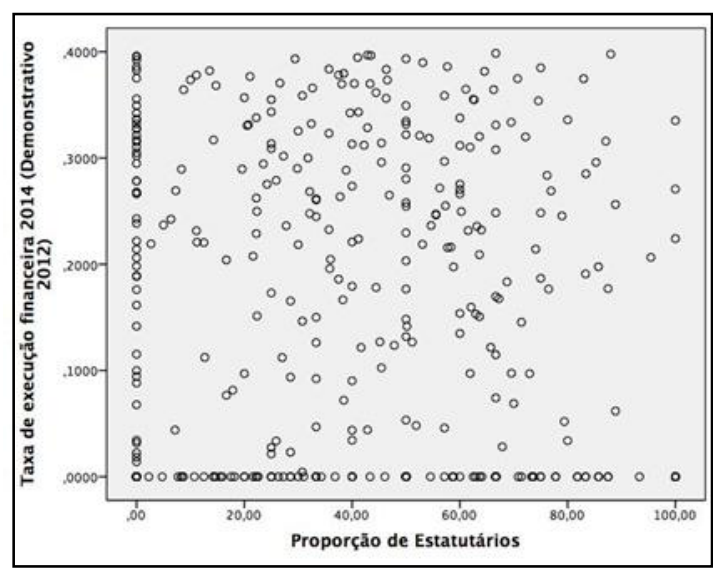

Gráfico 12

Dispersão da taxa de execução para municípios com $40 \%$ ou menos de execução em relação à proporção de sem vínculos, em 2014

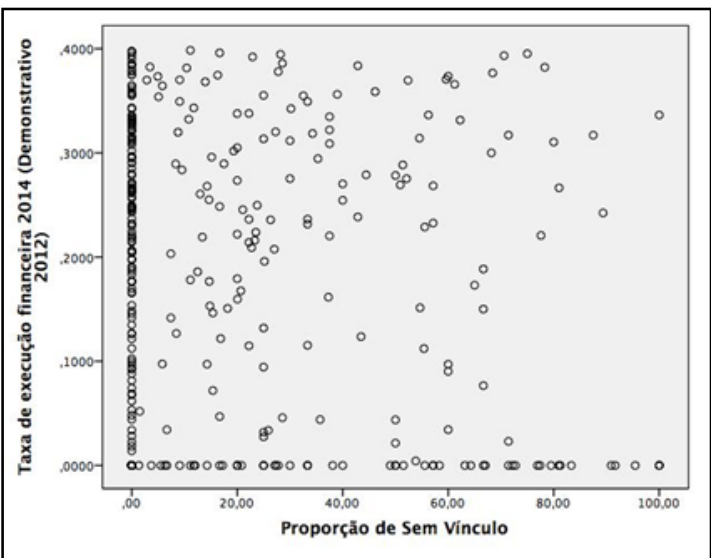

Fonte: Gráficos de 9 a 12 - Elaboração própria com base nos dados do Censo Suas e do Demonstrativo Sintético Anual da Execução Físico-Financeira acessado em 23 de março de 2015 no site do MDS.

Fizemos, então, um segundo exercício: verificar a correlação desses municípios com baixa taxa de execução e a proporção de recursos humanos sem vínculos empregatícios estáveis, considerando-se que este pode ser um indicador de rotatividade de trabalhadores que deve incidir diretamente na capacidade de gestão, dado que não há 
como assegurar o desenvolvimento de habilidades e competências necessárias para o desempenho esperado. A partir disso fizemos os Gráficos 11 e 12 de dispersão das duas medidas, ou seja, só dos municípios com menor taxa de execução para o demonstrativo de 2010 (ano de 2012) e para o de 2012 (ano de 2014) com a proporção de recursos humanos sem vínculos. O resultado continua desconcertante: também aqui, apesar de observarmos uma diminuição de casos entre os dois anos, não há nenhuma correlação entre ter uma baixa proporção de trabalhadores sem vínculo na assistência social e a capacidade de execução. A nuvem de dispersão pega a todos igualmente. Ou seja, ao contrário do que pressupõe a literatura sobre capacidade do Estado em suas diversas variantes, no caso estudado o fato de ter uma proporção alta de vínculos estáveis não garante um diferencial na capacidade de gestão municipal. Todavia, o seu inverso também contrariou a teoria, vínculos informais não pioram a taxa de execução, como esperado.

\section{Considerações finais}

Neste artigo apresentamos e descrevemos dados relacionados à capacidade de implementação e de gestão municipal da política de assistência social e sua distribuição espacial, buscando compreender se e em que medida características da burocracia municipal poderiam influenciar nos resultados municipais. Os achados são poucos, mas contundentes.

A literatura indica que a existência de uma burocracia estável, com perspectiva de carreira de longo prazo, é essencial para que o Estado desenvolva e exerça suas capacidades. A análise dos dados disponíveis sobre os vínculos dos profissionais da assistência social nos aponta que, no que se refere à variação dos vínculos empregatícios, não há dúvidas de que há padrões regionais e estaduais distintos agindo na conformação dos quadros municipais.

Apesar da predominância de vínculos estatutários para os assistentes sociais, os vínculos dos demais profissionais envolvidos variam regionalmente. Como reflexo do desenvolvimento econômico e social, no Nordeste e no Norte há uma predominância de vínculos temporários, bem como uma predominância da presença de agentes sociais em relação aos assistentes sociais. Isso denota uma fragilidade maior dos vínculos nessas regiões e, provavelmente, maior rotatividade dos quadros. Essas regiões também apresentam uma proporção muito maior de profissionais com apenas ensino fundamental e médio em comparação com o Sul e o Sudeste do país, o que indica a variação na profissionalização da burocracia. Esses dados mostram, portanto, a predominância de vínculos precários da maior parte dos profissionais da assistência social e a baixa profissionalização de parte significativa deles, especialmente em algumas regiões do país, o que informa sobre a baixa capacidade burocrática dos municípios no que tange à assistência social. 
Em relação à forma como esses indicadores de uma burocracia mais estável e com maior nível de formação se relacionam com os indicadores de serviços e com a taxa de execução, os resultados refutam a teoria. Eles mostram claramente que a implementação efetiva da política, mensurada tanto pelos índices do MDS quanto pela taxa de execução, não tem relação positiva com a capacidade burocrática instalada nos municípios, ou seja, os serviços são realizados e os recursos são executados, mesmo quando a capacidade burocrática é baixa. De acordo com todos os indicadores utilizados, é possível verificar que houve efetivamente uma melhora na execução dos municípios ao longo do período estudado. Todavia, há um destaque para o Nordeste, com o maior número de municípios com nível máximo de IGD-Suas, por exemplo, enquanto Sul e Sudeste apresentam os menores valores. Encontramos, nesse caso, um padrão regional que pode estar relacionado a demandas por proteção social mais prementes na região Nordeste (e, nela, principalmente nas regiões do semiárido) e que leva os municípios a utilizarem ao máximo os recursos federais.

Ao contrário do que se espera, há uma correlação espacial invertida entre nível de desenvolvimento econômico do município e sua capacidade de implementação. As regiões com indicadores maiores de pobreza, especialmente o Nordeste, são aquelas em que a taxa de execução é maior, apesar das variações internas à região. Há também uma autocorrelação espacial não generalizada das taxas de execução e do IGD-Suas. Ou seja, é possível afirmar que dentro dos estados há redes que elevam ou limitam a melhoria dos indicadores utilizados.

Outro achado é em relação ao porte populacional dos municípios. Não há diferenças significativas na capacidade de implementação entre os diferentes portes de município. Ou seja, não é possível afirmar que o fato de um município ter maior população Ihe dá maior capacidade de implementação, nem o inverso. Talvez a explicação, quanto aos municípios maiores, seja a concentração de demandas por proteção social, dada a forte migração rural-urbana vivenciada no país nos últimos 50 anos.

Por sua vez, se considerarmos os dados do IDCras, observamos que os municípios declaram realizar atividades acima do suficiente, independentemente da quantidade ou da profissionalização de seus recursos humanos. Isso nos sugere duas coisas: por um lado, uma demanda maior do que a capacidade instalada e, por outro lado, uma ameaça clara à qualidade dos serviços prestados. Somando-se a precariedade dos vínculos e a baixa profissionalização da área, pode-se supor que essa qualidade está comprometida, dados os padrões apontados pela própria política. Nesse caso, caberia uma investigação específica para melhor conhecer esses resultados.

Dentre as ocupações profissionais vinculadas ao Suas, destaca-se a de assistentes sociais, ainda que existam "vazios" identificados pela Rais nos estados do Amazonas, Roraima, Acre, Amapá, Goiás, Maranhão e Piauí, ou seja, em muitos lugares não há registro de assistentes sociais com vínculos formais, em especial em municípios 
das regiões Norte, Nordeste e Centro-Oeste. A Munic e o Censo Suas, por sua vez, evidenciam a prevalência da fragilidade dos vínculos de um conjunto de profissionais que atuam na política de assistência social (nos Cras e Creas), especialmente nas regiões Norte, Nordeste e norte de Minas Gerais, bem como a prevalência de contratação de celetistas em São Paulo. A situação fica ainda mais precária quando se toma como referência os profissionais de nível médio. No entanto, não encontramos nenhuma correlação entre tipo de vínculo e a efetiva execução dos recursos oriundos do governo federal.

Por fim, enfatizamos que os dados nos apontam que a capacidade de implementação e da gestão da política de assistência social nos municípios independe do tipo de vínculo dos profissionais e da existência de uma burocracia estável e profissionalizada, como a literatura tem enfatizado, e que constitui a capacidade administrativa do Estado. No caso da assistência social, nos parece que a implementação da política e a maior utilização dos recursos federais estão mais diretamente relacionadas às demandas por proteção social do que à capacidade burocrática instalada propriamente dita, o que pode ser decorrente de um processo de represamento de demandas que precisavam ser atendidas, em razão das desigualdades socioeconômicas prevalentes. Esses resultados mostram que há, aqui, um importante e fértil campo de estudos que possibilita ampliar e aprofundar os estudos sobre capacidades estatais.

Natália Guimarães Duarte Sátyro - Professora do Departamento de Ciência Política, Faculdade de Filosofia e Ciências Humanas, Universidade Federal de Minas Gerais.

E-mail: <nsatyro@gmail.com>.

Eleonora Schettini Martins Cunha - Professora do Departamento de Ciência Política, Faculdade de Filosofia e Ciências Humanas, Universidade Federal de Minas Gerais. E-mail: <eleonora.ufmg@gmail.com>.

Járvis Campos - Doutorando em Demografia do Centro de Desenvolvimento e Planejamento Regional (Cedeplar), Universidade Federal de Minas Gerais.

E-mail: <jarviscps@gmail.com>.

\section{Referências bibliográficas}

ABRÚcio, F. L. A importância dos arranjos intergovernamentais: potencialidades e dilemas na trajetória brasileira recente. In: DALLABRIDA, V. R. (org.). Governança territorial e desenvolvimento: descentralização político-administrativa, estruturas subnacionais de gestão do desenvolvimento e capacidades estatais. Rio de Janeiro: Garamond, 2011.

BATISTA, M. "Burocracia local e qualidade da implementação de políticas descentralizadas: uma análise da gestão de recursos federais pelos municípios brasileiros". Revista do Serviço Público, vol. $66, n^{\circ} 3$, p. 345-370, jul.-set. 2015. 
NATÁLIA GUIMARÃES DUARTE SÁTYRO; ELEONORA SCHETTINI MARTINS CUNHA; JÁRVIS CAMPOS

BRASIL. "Censo Suas 2010". Disponível em: <http://aplicacoes.mds.gov.br/sagi/ PainelPEI/Publicacoes/CensoSuas_2010.pdf>. Acesso em: 10 out. 2015.

. "Censo Suas 2011". Disponível em: <http://aplicacoes.mds.gov.br/sagi/PainelPEI/ Publicacoes/Censo\%20Suas\%202011_Final.pdf>. Acesso em: 10 out. 2015.

. "Censo Suas 2012". Disponível em: <http://aplicacoes.mds.gov.br/sagirmps/ ferramentas/docs/censo/CensoSuas_2012_final.pdf>. Acesso em: 10 out. 2015.

. "Censo Suas 2013". Disponível em: <http://aplicacoes.mds.gov.br/sagirmps /ferramentas/docs/CensoSuas_2013_completo.pdf>. Acesso em: 10 out. 2015.

. "Censo Suas 2014". Disponível em: <http://aplicacoes.mds.gov.br/sagi/publicacao_ eletronica/muse/Censo2014/index.html>. Acesso em: 10 out. 2015.

. Conselho Nacional de Assistência Social - CNAS. Resolução n 130, de 15 jul. 2005.

. Conselho Nacional de Assistência Social - CNAS. Resolução n 17/2011.

. Lei $n^{\circ} 12.435 / 2011$, que altera a Lei n 8.742/1993 (Lei Orgânica de Assistência Social).

. Ministério do Desenvolvimento Social e Combate à Fome (MDS). Política Nacional de Assistência Social. Brasília, 2004.

. Ministério do Desenvolvimento Social e Combate à Fome (MDS). Norma Operacional Básica: NOB/RH/Suas. Brasília, 2006.

. Ministério do Desenvolvimento Social e Combate à Fome (MDS). Norma Operacional Básica dos Recursos Humanos do Suas - NOB/RH, 2006.

. Ministério do Desenvolvimento Social e Combate à Fome (MDS). Norma Operacional Básica do Suas - NOB/Suas. Brasília, 2012.

. Ministério do Desenvolvimento Social e Combate à Fome (MDS). Portaria n 17/2012.

CARDoso JR., J. C. (org.). Burocracia e ocupação no setor público brasileiro. Rio de Janeiro: Ipea, 2011.

CingolAnI, L. The state of State capacity: a review of concepts, evidence and measures. Working Paper Series on Institutions and Economic Growth: IPD WP12.UNU-MERIT. 2013. Disponível em <http://pub.maastrichtuniversity.nl/25cb727f-2280-41f0-a1da-ecf3ac48230f>. Acesso em: 5 fev. 2015.

Cingolani, L.; Thomsson, K.; Crombrugghe, D. Minding Weber more than ever? The impacts of State capacity and bureaucratic autonomy on development goals. Working Paper Series on Institutions and Economic Growth: IPD WP12.UNU-MERIT. 2013. Disponível em:

<http://portal.unu.edu/news/7196>. Acesso em: 5 fev. 2015.

D'AraúJo, M. C.; LAMEIRÃo, C. Dirigentes públicos federais de alto escalão no governo Lula. In: CARDoso JR., J. C. (org.). Burocracia e ocupação no setor público brasileiro. Rio de Janeiro: Ipea, 2011.

DE VAUSS, D. Research design in social research. Thousand Oaks, CA: Sage, 2001.

EVANS, P.; RAUCH, J. E. "Bureaucracy and growth: a cross-national analysis of the effects of 'weberian' state structures on economic growth". American Sociological Review, vol. 64, $\mathrm{n}^{\circ}$ 5, $\mathrm{p}$. 748-765, October 1999. 
GaetANi, F.; HeRedia, B. "The political economy of civil service reform in Brazil: the Cardoso years". In: Red de gestión y transparencia del diálogo regional de política del Banco Interamericano de Desarrollo, 2002. Mímeo.

Gomide, A. A. Capacidades estatais para políticas públicas em países emergentes: (des)vantagens comparativas do Brasil. In: Gomide, A. A.; BosCHI, R. R. (eds.). Capacidades estatais em países emergentes: o Brasil em perspectiva comparada. Brasília: Ipea, 2016.

GouvÊA, G. P. Burocracia e elites burocráticas no Brasil. São Paulo: Paulicéia, 1994.

IBGe. Munic. Pesquisa de informações básicas municipais, 2012.

King, G.; KeOHAne, R.; Verba, S. Designing social inquiry. Princeton: Princeton University Press, 1994.

LouReiro, M. R.; Abrucio, F. L. "Política e burocracia no presidencialismo brasileiro: o papel do Ministério da Fazenda no primeiro governo Fernando Henrique Cardoso". Revista Brasileira de Ciências Sociais, vol. 14, n 41, p. 69-89, 1999.

Nogueira, R. P.; CARDOSO JR., J. C. "Tendências e problemas da ocupação no setor público brasileiro: conclusões parciais e recomendações de pesquisa". Revista do Serviço Público, Brasília, vol. 62, nº 3, p. 237-260, jul.-set. 2011.

OliveirA, A. "Burocratas da linha de frente: executores e fazedores das políticas públicas". Revista de Administração Pública, Rio de Janeiro, vol. 46, nº 6, p. 1.551-1.573, nov.-dez. 2012.

RAIS. Relação Anual de Informações Sociais, ano-base 2013. Brasília, DF, 2014.

SÁTYRo, N. G. D.; CUNHA, E. S. M. "The path of Brazilian social assistance policy post-1988: the significance of institutions and ideas". Brazilian Political Science Review, vol. 8, n 1, p. 80-108, 2014.

SKOCPOL, T. Bringing the State back in: strategies of analysis in current research. In: EVANS, P. B.; RUESCHEMEYER, D.; SKOCPOL, T. (eds.). Bringing the State back in. New York: Cambridge University Press, 1985.

SouzA, C. M. "Modernização e capacidade burocrática e financeira do Estado na política de assistência social" - Projeto de pesquisa submetido ao CNPq para solicitação de bolsa de produtividade em pesquisa. Agosto, 2010. Mímeo.

Weber, M. Economia e sociedade: fundamentos da sociologia compreensiva. Brasília: Ed. UnB, 1978.

\section{Resumo}

Análise espacial da burocracia da assistência social nos municípios brasileiros: notas para uma reflexão sobre a capacidade de implementação dessa política

O artigo apresenta e descreve dados relacionados à capacidade de implementação da política de assistência social e sua distribuição espacial, buscando compreender se e em que medida características da burocracia municipal poderiam influenciar os resultados. Nesse sentido, apresenta uma análise espacial da variação do perfil dessa burocracia conforme suas ocupações, tipos de vínculo e nível educacional, bem como a capacidade de implementação e gestão da política, verificada por meio da Taxa de Execução Financeira Ajustada do Fundo de Assistência Social. Foram utilizados indicadores do Censo Suas de 2010 a 2014 e dados da Relação Anual de Informações Sociais (Rais) de 2013 e da Pesquisa sobre os Municípios do IBGE (Munic) de 2012. Verificou-se a 
existência de padrões regionais e estaduais distintos quanto aos vínculos empregatícios, bem como quanto à profissionalização da burocracia, o que aponta para variações importantes na capacidade burocrática. No entanto, os dados apontam que a capacidade de implementação e da gestão da política de assistência social nos municípios independe do tipo de vínculo dos profissionais e da existência de uma burocracia estável e profissionalizada, ou seja, parece estar mais diretamente relacionada às demandas por proteção social do que pela capacidade burocrática instalada.

Palavras-chave: burocracia; assistência social; municípios; capacidade de implementação

\section{Abstract}

Spatial analysis of social assistance bureaucracy in Brazilian municipalities: notes for reflection on the implementation capacity of social-assistance policy

This paper presents and describes data related to the implementation capacity of social-assistance policy and its spatial distribution. It seeks to understand whether-and to what extent- certain characteristics of municipal bureaucracy can influence results. This paper relies on the Taxa de Execução Financeira Ajustada do Fundo de Assistência Social to present a spatial analysis of variation in the profile of social assistance bureaucracy, according to its roles, types of connections, and educational levels, as well as its implementation capacity and policy management. We use Suas Census indicators from 2010 to 2014, as well as data from the Annual Report on Social Information (Rais) of 2013 and from the Research on the Municipalities of IBGE (Munic). Analysis shows the existence of distinct regional and state patterns concerning employment relationships, as well as the professionalization of bureaucracy, which reveals important variations in bureaucratic capacity. However, the data indicate that the capacity of implementation and management of social assistance policies in municipalities is not related to the type of connections that the bureaucracy's personnel have to stability and professionalization. Rather, these capacities seem to be more directly connected to demands for social assistance than to bureaucratic capacity.

Keywords: bureaucracy; social assistance; municipalities; implementation capacity

\section{Resumen}

Análisis espacial de la burocracia de la asistencia social en los municipios: notas para la reflexión sobre la capacidad para implementar esta política

El artículo presenta y describe los datos relacionados con la capacidad de ejecución de la política de asistencia social y su distribución espacial, tratando de entender si, y en qué medida, las características de la burocracia municipal podrían influir en los resultados. En este sentido, se presenta un análisis espacial de la variación del perfil de esta burocracia como sus ocupaciones, tipos de vínculos y nivel de estudios, así como la capacidad de implementación y de gestión de la política, verificado por la Tasa de Ejecución Financiera Ajustada del Fondo de Asistencia Social. Utilizamos indicadores del Censo Suas de 2010 a 2014 y los datos de la Relación Anual de Informaciones Sociales (Rais) de 2013 y la Encuesta de municipios IBGE (Munic) de 2012. Encontramos la existencia de distintos patrones regionales y estatales con respecto a las relaciones laborales, así como la profesionalización de la burocracia, lo que apunta a cambios importantes en la capacidad burocrática. Sin embargo, los datos indican que la capacidad de implementación y la gestión de la política de asistencia social en los municipios no dependen del tipo de vínculo de los profesionales y la existencia de una burocracia estable y profesionalizada, es decir, parecen estar más directamente relacionados con las demandas de protección social que por la capacidad burocrática instalada .

Palabras clave: la burocracia; asistencia social; municipios; capacidad de implementación 


\section{Résumé}

Analyse spatiale de la bureaucratie de l'assistance sociale dans les communes: note de réflexion sur la capacité de mettre en œuvre cette politique

L'article présente et décrit les données relatives à la capacité de mettre en œuvre la politique $d$ 'assistance sociale et sa distribution spatiale, en essayant de comprendre si, et dans quelle mesure, les caractéristiques de la bureaucratie municipale pourraient influencer les résultats. En ce sens, I'article présente une analyse spatiale de la variation du profil de cette bureaucratie selon les professions, les types de liens et le niveau d'éducation, ainsi que selon la capacité de mise en oeuvre et de gestion des politiques, vérifiée grâce au Taux d'Exécution Financière Rajusté du Fonds de Protection Sociale. On a utilisé les indicateurs du Censo Suas de 2010 à 2014 et les données du Rapport Annuel d'Informations Sociales (RAIS) de 2013 et I'Enquête sur les communes de I'IBGE (Munic) de 2012. Il a été possible de vérifier l'existence de modèles régionaux distincts en ce qui concerne les relations de travail, ainsi que la professionnalisation de la bureaucratie, ce qui indique des différences importantes dans la capacité bureaucratique. Toutefois, les données indiquent que la capacité de mise en œuvre et de gestion de la politique d'assistance sociale dans les communes ne dépend pas du type de contrat de travail ni de l'existence d'une bureaucratie stable et professionnalisée, c'est-à-dire qu'elle semble être plus directement liée aux demandes de protection sociale qu'à la capacité bureaucratique installée.

Mots-clés: la bureaucratie; l'assistance sociale; municipalités; la capacité de mise en œuvre

Artigo submetido à publicação em outubro de 2015. Versão final aprovada em julho de 2016. 